\title{
Fragility curves for Italian URM buildings based on a hybrid method
}

\author{
A. Sandoli ${ }^{1}$ - G. P. Lignola ${ }^{1} \cdot$ B. Calderoni ${ }^{1} \cdot$ A. Prota ${ }^{1}$
}

Received: 17 March 2021 / Accepted: 10 June 2021 / Published online: 18 June 2021

(C) The Author(s) 2021

\begin{abstract}
A hybrid seismic fragility model for territorial-scale seismic vulnerability assessment of masonry buildings is developed and presented in this paper. The method combines expertjudgment and mechanical approaches to derive typological fragility curves for Italian residential masonry building stock. The first classifies Italian masonry buildings in five different typological classes as function of age of construction, structural typology, and seismic behaviour and damaging of buildings observed following the most severe earthquakes occurred in Italy. The second, based on numerical analyses results conducted on building prototypes, provides all the parameters necessary for developing fragility functions. PeakGround Acceleration (PGA) at Ultimate Limit State attainable by each building's class has been chosen as an Intensity Measure to represent fragility curves: three types of curve have been developed, each referred to mean, maximum and minimum value of $P G A$ s defined for each building class. To represent the expected damage scenario for increasing earthquake intensities, a correlation between PGAs and Mercalli-Cancani-Sieber macroseismic intensity scale has been used and the corresponding fragility curves developed. Results show that the proposed building's classes are representative of the Italian masonry building stock and that fragility curves are effective for predicting both seismic vulnerability and expected damage scenarios for seismic-prone areas. Finally, the fragility curves have been compared with empirical curves obtained through a macroseismic approach on Italian masonry buildings available in literature, underlining the differences between the methods.
\end{abstract}

Keywords Hybrid method · Fragility curves · URM buildings · Typological classification · Territorial-scale

\section{Introduction}

Due to its particular position between the African and Euro-Asiatic plate, Italy is recognized as one of the countries of the Mediterranean basin affected by high-frequency and high-intensity earthquakes. Starting from the 1908 Messina and Reggio Calabria's

A. Sandoli

antonio.sandoli@unina.it

1 Department of Structures for Engineering and Architecture (Di.St.), University of Naples Federico II, via Claudio 21, 80125 Naples, Italy 
earthquake (with $M_{\mathrm{w}}=7.1$ and 100,000 victims estimated) up to the last 2016-2017 Central Italy seismic sequences $\left(M_{\mathrm{w}}=6.5\right)$, severe seismic events affected Italy during the twentieth century. A brief reconnaissance of the most important earthquakes occurred in Italy in the last century is reported in Fig. 1, represented in terms of magnitude $\left(M_{\mathrm{w}}\right)$ and Mercalli-Cancani-Sieber $(M C S)$ macroseismic scale by means of histograms. Consequences of these earthquakes were often devastating not only for the reconstruction costs (about 180 billion euros in the last fifty years) but also for the casualties (more than 100,000, estimated in the last century) (DPC 2018).

Seismic vulnerability assessment at territorial level represents a fundamental tool to plan economical and human resources for mitigating the National seismic risk, especially in those countries exposed to a high seismic hazard. With this aim, different methods-based on empirical, mechanical (or analytical), expert-judgment and hybrid approaches - to assess seismic vulnerability and to predict the damage scenarios have been developed over the years by researchers (Calvi et al. 2006). Each method provides a classification of masonry buildings and defines the relative fragility curves useful for large-scale seismic assessment.

In the case of empirical methods, both buildings' classification and fragility curves come from the statistical elaboration of data collected in post-earthquake surveys relative to damaged buildings. Their main advantage is that real observed data, when correctly interpreted, are a realistic source of information which takes into account building stock features and ground motion effect. On the other side, disadvantages related to the heterogeneity of data of post-earthquake surveys or the unavailability of a sufficient number for several intensities of earthquakes make their results questionable (Rota et al. 2008). Due to the low-frequency of occurrence, few datasets are available either for low and very high-intensity events, making difficult to choose representative cumulative density functions to define fragility curves (Kappos et al. 2006).

Based on empirical approaches, different studies to estimate seismic vulnerability in Italy have been presented in literature (Di Pasquale et al. 2005; Rota et al. 2008; Zuccaro and Cacace 2015; Del Gaudio et al. 2019; Donà et al. 2020; Polese et al. 2020). Among these, Rota et al. (2008) developed an extensive investigation based on statistical processing of damage data relating to 150,000 Italian residential buildings affected by earthquakes (from 1980 Irpinia's to 2002 Pollino and Molise's earthquake) aimed at developing the fragility curves. A conspicuous number of buildings classes (about

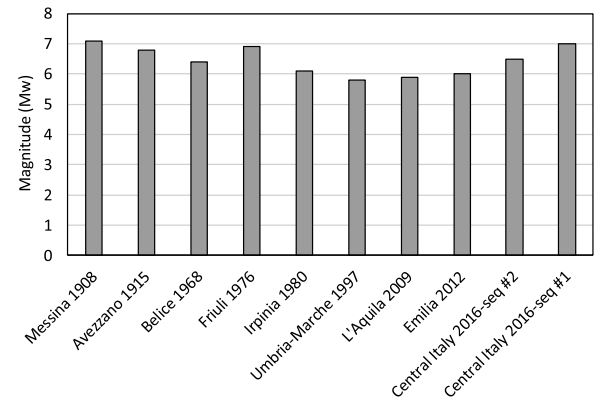

(a)

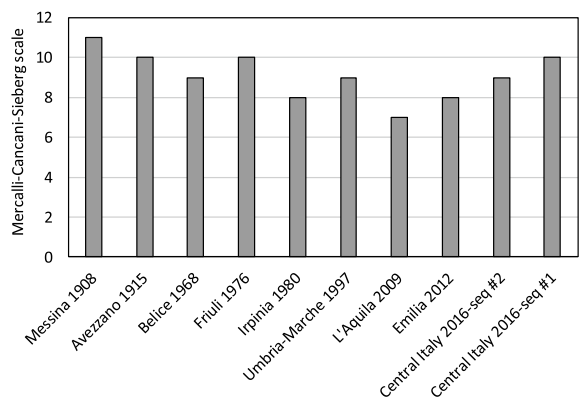

(b)

Fig. 1 Reconnaissance of the most severe Italian earthquakes of the 20th century: (a) Magnitude, (b) MCS scale 
16 for masonry buildings), differentiated as a function of masonry types, floors and the number of storey resulted.

Recently, Del Gaudio et al. (2019) defined empirically-derived typological fragility curves for masonry buildings after the 2009 L'Aquila's earthquake based on damage data of 32,520 residential buildings. Twenty buildings classes differentiated for masonry type, vertical and horizontal structural arrangement resulted, and typological fragility curves were developed in compliance with the damage levels defined by European Macroseismic Scale (EMS98).

In the case of mechanical methods, fragility curves are the result of statistical elaboration of data derived from numerical analyses performed on case study buildings, real or simulated through Monte Carlo stochastic analyses (Rota et al. 2010; Belliazzi et al. 2021). With respect to empirical methods, mechanic-based approaches could result more effective when a large dataset of information on building features are available. Consequently, the use of simplified structural models aimed at reducing the computational effort for both in-plane and out-of-plane analyses is justified, but taking into account that uncertainties related to approximations in the structural modelling and on the material properties can affect negatively the structural response (Rota et al. 2014; Quagliarini et al. 2017; Sandoli et al. 2020).

Expert-judgement methods provide typological fragility curves from statistical processing of information provided by a team of experts which estimate feasible damage level and structural behaviour for structures with different characteristics. This necessitates, on one side, of an appropriate knowledge of the constructional techniques and structural features of buildings stock and, on the other side, mastery of the theoretic structural behaviour. ATC-13 (ATC-1985) standards demonstrated that judgementbased approaches could over-estimate the structural damage and the results could be affected from the sensibility and technical knowledge of the method developer. A comparison among the different methodologies for assessing the seismic vulnerability of about a thousand school buildings located in Naples (Italy) has been conducted in Ceroni et al. (2020), and advantages and disadvantages of each method was highlighted.

To overcome the limitations inherent in each method, hybrid methodologies are often preferred by researchers. A macroseismic approach based on combination of empirical data and expert-judgement was presented in Bernardini (2004), while a mixed macroseismic and mechanical model was proposed in Lagomarsino and Giovinazzi (2006). In the latter, the vulnerability of building's classes is defined through vulnerability curves, within the macroseismic method, and through capacity curves within the mechanical method. In 2006, Kappos et al. (2006) presented fragility curves for masonry and Reinforced Concrete (R.C.) buildings in Greece based on a hybrid method; the method combines statistical data derived from earthquake-damaged constructions with the results of nonlinear static or dynamic analyses conducted on a large number of building types.

Recently, a mixed mechanics-based fragility model for Italian unreinforced masonry $(U R M)$ building was proposed by Donà et al. (2020), based on information derived from the National Institute of Statistics (ISTAT) in combination with expert-judgment observational procedure. It divided residential $U R M$ buildings in ten classes by age of construction and number of storeys. The software Vulnus 4.0. processes information on buildings features, material strength, types of floors, etc., and calculates maximum bearable Peak-Ground Acceleration (PGA) used to derive fragility for the defined classes (Valluzzi 2009). 


\subsection{Research significance}

This paper presents a hybrid methodology to define typological fragility curves valid for territorial or regional scale seismic vulnerability assessment, based on the combination of mechanical and expert-judgment approaches. The judgment-based part classifies the Italian $U R M$ buildings into five homogeneous structural-typological classes, while the mechanical part defines the numerical parameters necessary for developing the fragility functions.

The proposed classification is the result of an observational approach that matches the authors' experience developed in post-earthquake surveys (for the last forty years) with information available in literature. It arises from a close correlation among (i) age of construction (in turn related to the evolution of the seismic Codes over the years), (ii) structural characteristics of the buildings (i.e., material types, horizontal and vertical structures, seismic devices, etc.), and (iii) seismic behaviour and damages observed in post-earthquake situations. Together, these three factors contribute to define the overall seismic behaviour, considered the real discriminant that allows the subdivision in typological classes (Calderoni et al. 2020; Sandoli and Calderoni 2021).

For each building class, results of numerical analyses conducted on buildings prototypes have been collected aiming at elaborating a database to define the fragility curves. $P G A$ bearable by each building class at Ultimate Limit State has been chosen as the main Intensity Measure (IM) to represent fragility curves.

To have a more reliable and complete representation of the seismic vulnerability, a range of variability of the fragility curves has been considered: three different curves have been developed for each building class, differentiating the statistic variables as a function of mean, maximum and minimum bearable $P G A$ s.

Such curves have been also correlated with the Mercalli-Cancani-Sieberg (MCS) intensity scale, allowing for a representation of the expected damage scenario at increasing seismic intensities.

Results showed that the proposed methodology gives rise to realistic typological fragility curves, representative of the seismic vulnerability and damage scenario observed for $U R M$ Italian building stock after seismic events. Moreover, fragility curves derived via a hybrid method have been also compared with those obtained with empirical methods (i.e., based on EMS98) and the differences highlighted.

\section{Methodology}

Hybrid methods are recognized as effective solutions to develop fragility models. In the proposed methodology expert-judgment is combined with a mechanical approach: the first provides a structural-typological classification of the Italian buildings as a function of the recurrent types on the territory, while the second provides the mechanical parameters necessary to elaborate fragility curves. A conceptual map of the adopted methodology is represented in Fig. 2, while in the following Section it is described in detail. 


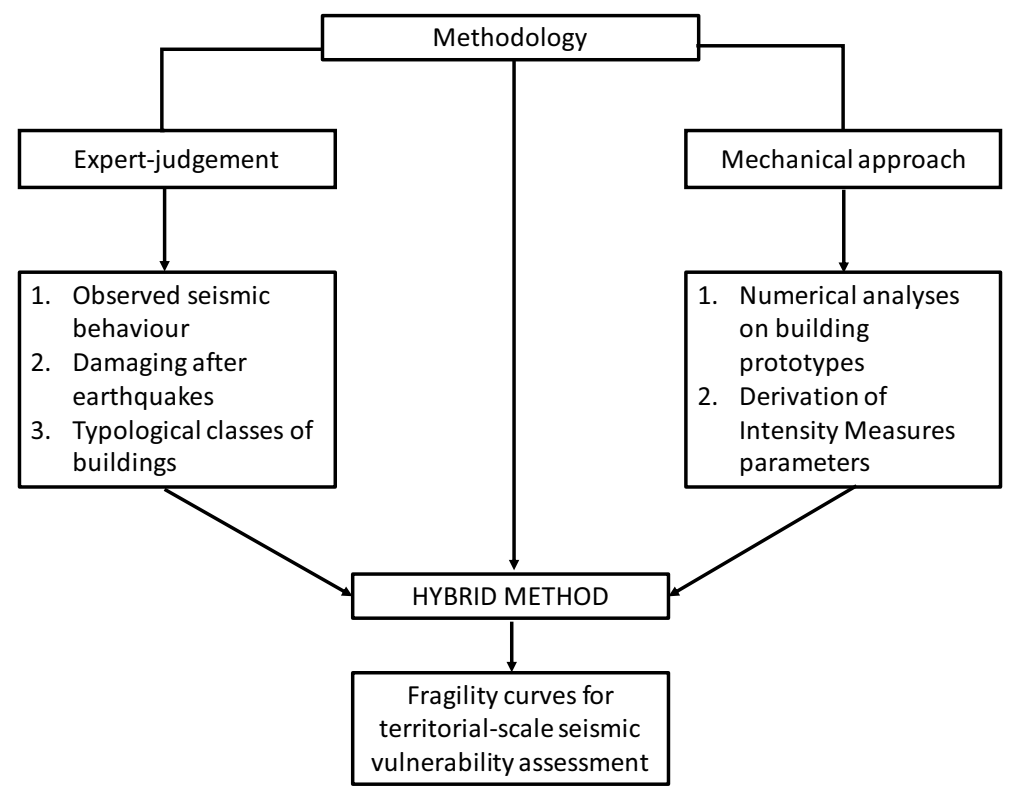

Fig. 2 Conceptual map of the proposed methodology

\subsection{Expert-judgment contribution}

Dividing residential $U R M$ buildings in a reduced number of homogeneous typological classes, representative of the whole Italian buildings stock, plays a crucial role to develop fragility models applicable on the whole National territory with minimum effort and errors.

A key issue is that the term 'masonry building' includes a very large set of buildings, each characterized by different material properties, structural features (i.e., seismic-resistant devices, floors, roofs, etc.) and details. As a consequence, their structural behaviour under seismic actions can be also significantly different to each other.

Despite these differences, a fairly close correlation among the age of construction, structural typology and observed seismic behaviour and damaging after earthquakes exists (Di Ludovico, 2017; Calderoni et al. 2020; Sandoli and Calderoni 2021). They represent the key factors for defining the classification and together contribute to define

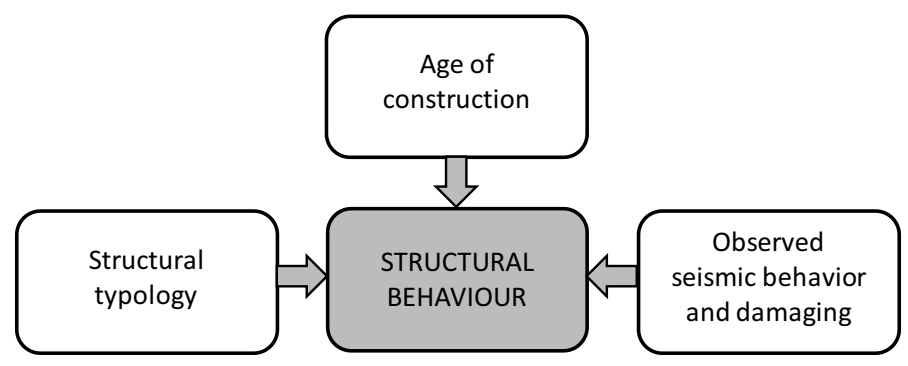

Fig. 3 Correlation among the elements which define the structural-typological classification 
and differentiate the global seismic behaviour of the buildings typologies. This latter is considered as the real discriminant of the classification that provides the subdivision in structural-typological classes (Fig. 3).

The classification is the result of the in-field authors' experience developed in the aftermath of the most severe earthquakes that occurred in the last forty years in Italy, combined with the research activity conducted in academia. Even if in different ages, the authors have been involved by the Italian Department of Civil Protection $(D P C)$ in the activities aimed at post-seismic usability and damage assessment of buildings hit by earthquakes. Moreover, they are now engaged in the CarTiS research project (promoted in collaboration between DPC and ReLUIS) whose scope is that of mitigating the seismic risk in Italy.

Such activities allowed observing damaged buildings closely and correlating the type of damage to both structural features and ages of construction. Part of such activities are documented in specific scientific papers, e.g. Calderoni et al. (2011), Di Ludovico et al. (2017), De Martino et al. (2017) and Calderoni et al. (2020).

Moreover, technical manuals or books (Pagano 1968; Baila et al. 2011; Ghersi et al. 2011), restoration and consolidation manuals (Mastrodicasa et. al 1943; Carbone et al. 2001) and past Italian Codes have been also examined to ensure a correct representativeness of the proposed typologies with respect to the buildings types diffused on the whole territory. This allowed for a better correlation among structural typologies, constructional techniques, types of material, methods of interventions, structural details, and ages of construction.

Age of construction is probably the most relevant parameter for the differentiation in typological classes. In the majority of literature papers, time intervals are defined as those between two consecutive ISTAT (National Institute of Statistics) censuses; thus, the first building class refers to constructions erected before 1918, the second collects buildings erected from 1919 to 1945 and so on up to constructions built after 2001 (Del Gaudio et al. 2019; Rosti et al. 2020). This is an effective way for identifying the buildings' constructional features included in the ISTAT database (e.g., type of materials and number of storeys), but it does not take into account the years of introduction of the Codes in an explicit way.

Dates of Codes introduction are important because new constructional rules or structural details were gradually introduced, often decisive to differentiate the global seismic behaviour of the constructions. In the proposed classification, age of construction is recognized as a function of the years of implementation of new Codes or other specific Regulations. Typically, new Codes were released after significant seismic events and could assume local (i.e., limited to the zones affected by earthquakes) or National valence.

Such ages represent a basic time interval valid for all Italian Regions, but they can be susceptible to modifications depending on specific requirements due to the municipal urban planning or other special events that have affected a specific area. Then, further time intervals and/or new structural typologies can be added when necessary for assessing the seismic vulnerability of an area.

Anyhow, the ISTAT database containing data of about seven millions of masonry buildings has been analysed and elaborated to highlight their evolution over the years, both in Italy (Fig. 4a) and in its macro-Regions (north-west, north-east, centre and southFig. 4b). By looking at Fig. 4a and b, the great part of masonry buildings date back before the second world war, with a great concentration of them before 1918. During the post-war reconstruction (i.e., 1960-1970) the number of masonry buildings decreases in the face of other structural typologies, that in Italy consist almost totally of R.C. buildings. 


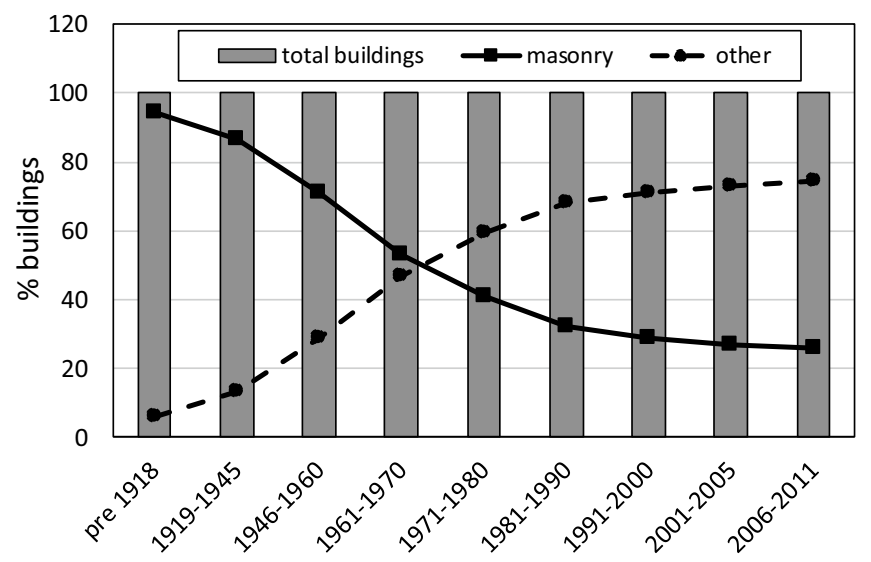

(a)

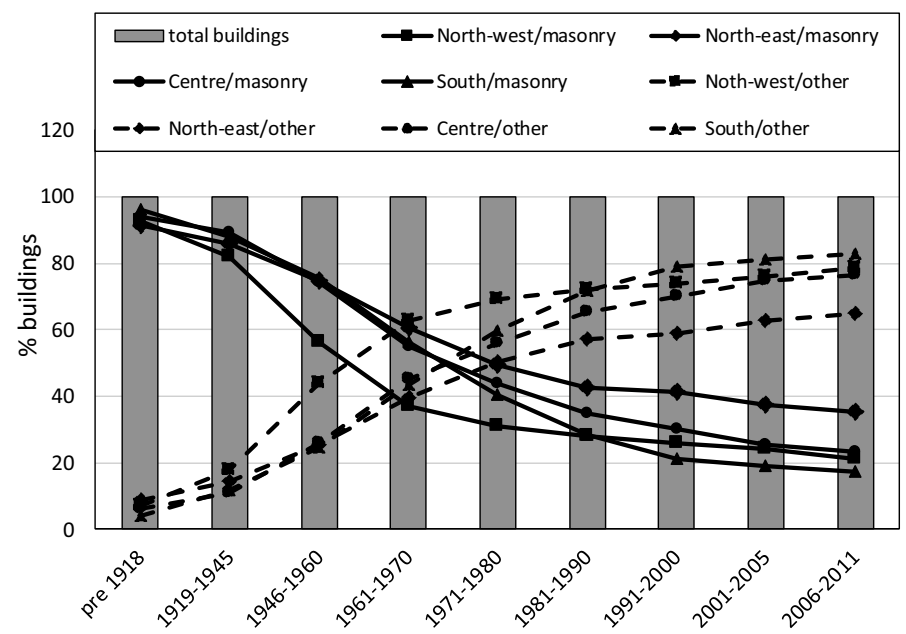

(b)

Fig. 4 Buildings percentage in Italy from ISTAT database: (a) total percentage in Italy, (b) percentage divided by macro-Regions

Structural typology regards the structural arrangement of the constructions, including type of horizontal and vertical structures. According to literature, types of floors have been differentiated as a function of the material, having in mind that different materials could require diverse structural solutions that in turn influence (or change) the overall seismic response of the construction.

Basically, in historical constructions, floors consist of in-plane deformable structures made with masonry vaults or timber/iron beams, while in modern buildings, floors consist of in-plane rigid elements made with R.C. or steel beams and with an upper reinforced slab.

With respect to other literature works, vertical walls assume a different significance in this paper. The authors believe that the seismic behaviour of the buildings depends firstly on the structural-typological characteristics of the construction, intended as effectiveness 
of wall-to-wall or wall-to-floor connections, amount of in-plane stiffness of floors, presence of ties, geometry of piers and lintels, amount of gravity loads, and secondly on the presence of transversal connections along the wall thickness, masonry material and its texture. The great part of the literature papers considers the masonry material and its texture as the key parameters which rule the seismic response of the constructions and, consequently, governs the typological classifications (EMS98). Contrary to this, in this paper the intrinsic properties of materials and their texture can improve or worsen the basic seismic behaviour without modifying the seismic capacity of the constructions significantly (Sandoli and Caderoni 2021). On the other side, it is evident that, on equal terms, the better the masonry properties and quality, the more the structure can resist to seismic actions.

Furthermore, the authors believe that the correlation between type of masonry material and ages of construction is not at all valid for the Italian Regions (especially if referred to historical constructions), because in Italy the type of masonry is strictly related to the materials available in a geographical area. As an example, in the Central Apennine area irregular calcareous stones were mainly used, while in the South and North Apennine tuff stones and clay-bricks respectively. Similarly, also the type of mortar changes Region by Region: in South Apennine pozzolanic-based mortar was used most, while lime mortar in North-Central zones (ISPRA 2021). However, type of used material as a function of the geographic area has been specified for each building class (see Appendix).

In the perspective of an observational approach, either observed seismic behaviour and damaging following to an earthquake are fundamental for including buildings with similar features into the same typological class. Post-earthquake inspections allowed to identify the role played by technological features and structural details on the overall seismic behaviour of the construction and to differentiate the buildings typologies. A strict correlation between observed seismic behaviour/damaging and age of introduction of Codes has been also noted, in fact rules introduced by the Codes changed the nature of the buildings and differentiated their seismic response.

\subsection{Mechanical contribution}

Based on numerical analysis, the mechanical approach provides the parameters for developing the fragility functions and represents also an effective support to validate the buildings' classification.

Aimed at evaluating representative $I M$ parameters required to derive the fragility curves, results of nonlinear (static and dynamic) analyses have been collected in advance. They come from analyses conducted on real case study buildings or from statistical simulations (i.e., Montecarlo analysis). In this paper results referred to real case studies have been preferred, because they were considered more representative of the structural features of the constructions with respect to statistical simulations.

\section{Evolution of the seismic codes in Italy}

The evolution of seismic Regulations in Italy is related to the occurrence of catastrophic events. In Table 1 a historical overview of the Italian seismic Codes is reported; in the same Table the relative precursor seismic event, the geographic area and the types of buildings to which the Codes were referred to, are indicated. 
Table 1 Evolution of the Italian seismic Codes

\begin{tabular}{llll}
\hline Seismic event & Code's name & Validity & Type of buildings \\
\hline Messina and Reggio 1908 & RD (1909) & Area hit by earthquake & New and existing \\
Avezzano 1915 & RD (1915) & Area hit by earthquake & New and existing \\
Mugello 1919 & RD (1920) & Area hit by earthquake & New and existing \\
Garfagnana 1920 & RD (1921) & Area hit by earthquake & New and existing \\
Irpinia 1930 & RD (1935) & Area hit by earthquake & New and existing \\
Veneto-Friuli 1936 & RD (1937) & All Italian Regions & New \\
Irpinia 1962 & L (1962) & All Italian Regions & New \\
Belice 1968 & MD 1975 & All Italian Regions & New \\
Irpinia 1980 & MD (1981) & All Italian Regions & Existing \\
Umbria Marche 1997, Molise 2002 & MD (1987) & All Italian Regions & New \\
& IBC-08 and & All Italian Regions & New and existing \\
& relative Recom- & All Italian Regions & New and existing \\
mendations & & \\
L'Aquila 2009, Emilia 2012, Central & IBC-18 and & All Italian Regions & New and existing \\
& relative Recom- & & \\
\hline & mendations & & \\
\hline
\end{tabular}

Before listing the various Codes, it is interesting to highlight that until 1987 (Ministerial Decree MD 1987) no specific design rules were provided in Italy for masonry buildings and that only rules-of-art handed by the masons over the years were included in the Codes. Nevertheless, the analysis of the past seismic standards is important for defining the main structural features of masonry constructions as a function of the age of the construction.

The first basic design rules for masonry buildings were introduced by the Royal Decree (RD 1909), after the 1908 Messina and Reggio Calabria's earthquake. RD (1909)—which can be considered as the precursor of the 'modern' seismic Codes-provided requirements for reconstruction and repairing of damaged masonry buildings, valid in those areas hit by earthquake only. It included specific rules aimed at preventing the intrinsic vulnerabilities of existing buildings (mainly out-of-plane failure modes) and was the first Italian document that defined a method for calculating the horizontal seismic actions as a function of the masses of buildings. Similarly, after the 1915 Avezzano's, 1919 Mugello's and 1920 Garfagnana's earthquakes relative RDs were introduced for the reconstruction process of those areas (Table 1).

Common to all these Codes, they were drafted on the basis of observed damages and limited the use of vulnerable elements that caused the collapse of the buildings such as: masonry vaults (except for the ground floor), cantilevered stairs, arches, poor quality masonry or thrusting roofs. Moreover, such Codes introduced for the first time the adoption of metal-ties for preventing out-of-plane failure modes of the façade walls. It is interesting to point-out that metal-ties were suggested not only for strengthening damaged existing buildings, but also for new constructions. Concerning the new constructions, maximum building's height, number of storeys, minimum thickness of the walls and maximum distances among resistant-walls were also provided.

These prescriptions were substantially confirmed in all the subsequent codes released after the 1930 Irpinia's and 1936 Veneto-Friuli's earthquakes, and were valid in all those areas classified as 'seismic' by the RD (1927). 
In the history of the Codes, a crucial date is represented by 1937. In this year, the RD (1937) was released, mandatory for all Italian Regions, which introduced new important constructional rules for masonry buildings that changed the way of conceiving the masonry structures: in fact, R.C. ring beams and R.C. floors (provided of top reinforced slab) became mandatory at each floor level for new masonry constructions. This date marks a crossing point from old (or 'ancient') to 'modern' masonry buildings, both characterized by a significantly different seismic behaviour (as better discussed in the Sect. 4). Despite that R.C. elements were explicitly required for new constructions, no indication on minimum steel reinforcement percentages to include in the top slabs were provided by the RD (1937). The constructional rules for R.C. slabs were introduced in the RD (1962) only, which provided indications on minimum slab's thickness and minimum transversal steel reinforcements. For the lintels over the openings, first regulations were introduced in the codes prior to 1962 in which (at least) $80 \mathrm{~cm}$ of anchorage inside the adjacent masonry was prescribed (but in the codes of 1962 this requirement was removed).

As shown in Table 1, after 1937 a series of codes were introduced as a consequence of new seismic events. Regarding the anti-seismic provisions, the main core of these documents remained the same of the RD (1937). But new indications regarding geometrical limitations of the structural elements or to the building arrangement were gradually introduced. For instance, blocks holes' ratio appeared in the MD (1975), while hollow blocks compressive strength in the MD 1984. Again, limitations about both vertical dimensions (maximum height of the building, maximum inter-story height and maximum storey number) and horizontal dimension (maximum distance between load-bearing walls, maximum distance between wall and buttress, minimum wall thickness, and minimum buttresses width and thickness) were introduced in MD (1996), as well as the maximum walls' slenderness (defined as the ratio between thickness and height of the wall) and their minimum cross-section enlargement at different storey.

Finally, in the modern Codes, i.e. introduced from 1996 onwards, more detailed indications concerning the seismic design of new masonry structures and methods for seismic assessment of existing ones have been included.

\section{Structural-typological classification of URM buildings}

Five different typological (or vulnerability) classes, indicated with the acronyms from $U R M-1$ up to $U R M-5$, have been considered as representative of the recurrent Italian residential $U R M$ buildings.

A general description of the five building classes is reported in the following. A summary containing detailed information on ages of construction, types of floors and of materials (as a function of the geographic zones) is reported in the Appendix.

\subsection{Ancient buildings}

The class of the 'Ancient Buildings' (URM-1) includes the constructions erected before 1910 and represents the prevalent typology in the Italian historical centres. In the majority of cases they were fabricated in compliance with the empirical rules in force at that time of construction, handed down by oral tradition.

Ancient Buildings consist of load-bearing masonry walls and floors made with masonry vaults or wooden/iron parallel beams simply supported on the walls. The poor 


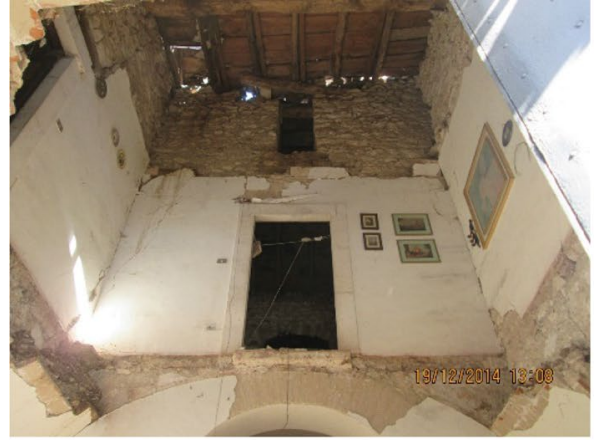

(a)

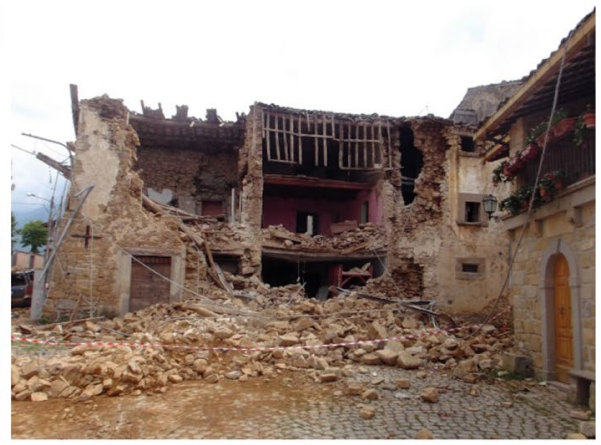

(b)

Fig.5 Ancient Buildings (URM-1): (a) building with masonry vaults damaged from 2009 earthquake in L'Aquila (Abruzzi Region), (b) building with wooden floors damaged from 2016 to 17 Central Italy earthquake in Amatrice (Lazio Region)

effectiveness (or sometimes the absence) of connections between façades and transversal walls and between walls and floors, makes the perimetral walls (or portions of them) prone to out-of-plane failure mechanisms under seismic actions. This behaviour, typical of the ancient constructions, has been recognized in almost all the Italian historical centres affected by medium and high-intensity seismic events (Calderoni et al. 2011; Penna et al. 2014).

In Fig. 5 two Ancient Buildings damaged during the 2009 L'Aquila (Italy) earthquake are represented. In Fig. 5a a two-storey masonry building made with full-height masonry walls and thin-walled vaults at each level is represented. Vertical cracks in the corners of the building denote the activation of out-of-plane mechanisms, while some internal masonry vaults are collapsed (further details concerning the damage state are reported in Sandoli and Calderoni 2021). Conversely, Fig. 5b illustrates the case of an Ancient Building having wooden floors and hit by the 2016 Central Italy earthquake: due to the not effective wall-to-wall and wall-to floor connections, façade wall collapsed out-of-plane. Moreover, the crumbled masonry at the foot of the building allows to imagine that also the bad masonry quality has furtherly aggravated the seismic response of the entire construction.

This class contains buildings that have not been subjected to seismic retrofit interventions over the years, although today located in seismic-prone areas as a consequence of the latest seismic macro-zoning of the Italian territory released by Italian Building Code (IBC-18), that declared the whole territory as seismic.

In detail, URM-1 buildings have been erected before 1937 in non-seismic zones and before the year of introduction of the specific seismic Codes for the zones affected by earthquakes from 1908 to 1937. As highlighted in the Sect. 3, 1909 and 1937 are two dates of fundamental importance for the evolution of seismic Codes in Italy: (i) the RD (1909) is the first document that provided requirements for strengthening and repair of damaged masonry buildings (even if limited to the zone of Messina and Reggio Calabria hit by the earthquake) introducing rules aimed at preventing the main intrinsic vulnerabilities of masonry buildings (i.e., out-of-plane of the façade walls), (ii) 1937 represents the year in which no more Ancient Buildings could be erected in Italy as a consequence of the introduction of a new Regulation (RD 1937). 


\subsection{Improved-ancient buildings}

The occurrence of earthquakes and the introduction of new Codes (even if limited to a restricted geographic areas) led to the typology of the Improved-Ancient Buildings (URM2). It collects buildings erected before 1937 in non-seismic areas and those constructed before the year of introduction of the specific seismic Codes for zones hit by earthquakes from 1908 to 1937 (declared as seismic following to the earthquakes), but which have been subjected to retrofit interventions as a consequence of seismic damages. Thus, basic materials and structural features remain the same of $U R M-1$, except for retrofit interventions.

Thanks to the introduction of tie systems and/or similar anti-seismic devices, the connections between orthogonal walls and between floors and walls were improved. Postinterventions, seismic performances of the constructions change significantly: they are no longer ruled by out-of-plane but by in-plane strength, stiffness and ductility of piers and spandrels (despite that floors remain deformable in-plane) (Tomazevic 1999).

Such behaviour has been observed on Improved-Ancient Buildings hit by 2009 L'Aquila or 2016 Central Italy events, where thanks to the adoption of steel-ties ruinous collapses have been prevented. Numerical analyses also confirmed the enhancement of the seismic performances of the strengthened buildings, because considerable increases of seismic capacity and damage reduction in comparison with unstrengthen constructions (URM-1) resulted (Magenes et al. 2014; Calderoni et al 2016a; Sandoli et al. 2021).

Two examples of URM-2 buildings, strengthened with steel-ties and damaged by the 2009 L'Aquila earthquake are represented in Fig. 6. It shows piers and spandrels affected by in-plane diagonal cracks as evidence of the activation of an in-plane behaviour under seismic actions.

\subsection{Modern buildings}

The introduction of the RD (1937) legitimized the birth of the Modern Buildings (URM-3), recognized as the seismic-resistant solution within the current seismic Codes still today (IBC-18).

RD (1937) was a revolutionary Code because it changed the structural conception of the buildings. New rules addressed towards a more performant box-like behaviour under seismic actions: explicit reference to floors made with R.C. elements appeared for the

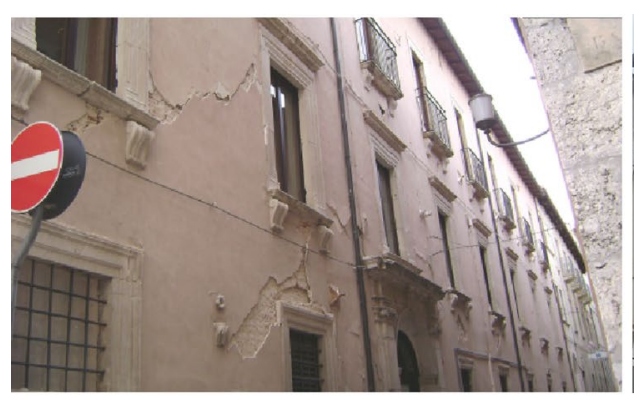

(a)

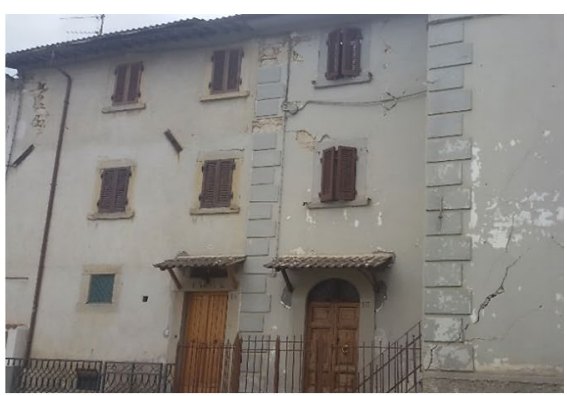

(b)

Fig. 6 Improved Ancient Building (URM-2): a building damaged from 2009 earthquake in L'Aquila (Abruzzi Region), b building damaged from 2016 to 17 Central Italy earthquake in Amatrice (Lazio Region) 
first time, adoption of R.C. ring beams connected to both floors and walls became mandatory at each story, as well as lintels effectively connected to the adjacent piers were required.

The introduction of in-plane stiff floors (i.e., provided of top R.C. slab) and R.C. ring beams represented an important measure for the seismic safety of masonry buildings. The latter interrupted the vertical continuity of the walls at each story and limit the possibility of out-of-plane collapse mechanisms to the inter-story height of the buildings (e.g., out-of-plane flexure). The walls are forced to behave in-plane and their seismic resistance depends on geometry of piers and spandrels, amount of gravity loads, constraint conditions and mechanical properties of materials (Tomazevic 1999; Gesualdo et al. 2019). Moreover, the in-plane rigid diaphragms allows to share the seismic forces among the resistant walls as a function of their in-plane stiffness, instead of as a function of the tributary area as in the case of URM-2.

The effectiveness of these provisions and the satisfactory seismic behaviour of the Modern Buildings has been demonstrated after main subsequent earthquakes. L'Aquila and Irpinia's, as well as Friuli's earthquakes, proved that global collapses were very rare and limited also for high-intensity earthquakes and imputable to constructional defects when occurred. An extensive analysis on the seismic behaviour and damaging of Modern Buildings is reported in Calderoni et al. (2020) with reference to 2009 L'Aquila's earthquakes; while, for Irpinia's and Friuli's earthquakes a detailed discussion is reported in Pagano (1990) and in Tomazevic (1999), respectively.

Also numerical analyses performed on real case study buildings highlight the good seismic performance and the achievement of significant seismic capacity of URM-3 building's typology (Calderoni et al. 2016a, b; Lagomarsino et al. 2019).

Modern Buildings include not only constructions erected after 1937 in non-seismic zones, but also those constructed according to the specific Codes issued from 1909 onwards for the zones affected by earthquakes (declared as seismic zones in advance).

Two earthquake-damaged Modern Buildings, the first located in L'Aquila and the second in San Severino Marche (hit by 2016 earthquake) are represented in Fig. 7. In both cases the seismic provisions required by RD (1937) have inhibited out-of-plane

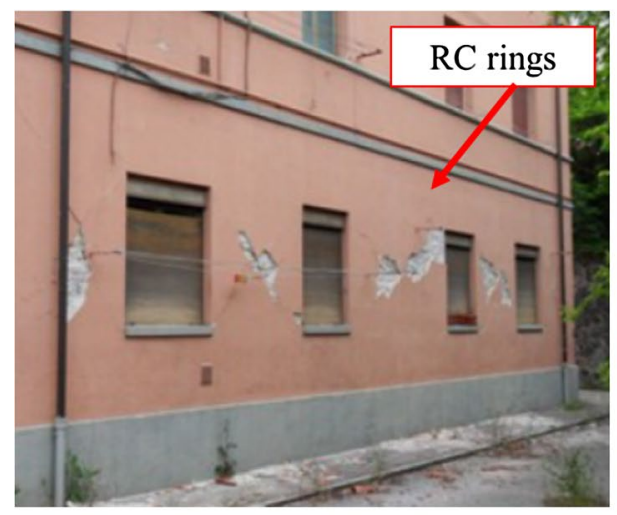

(a)

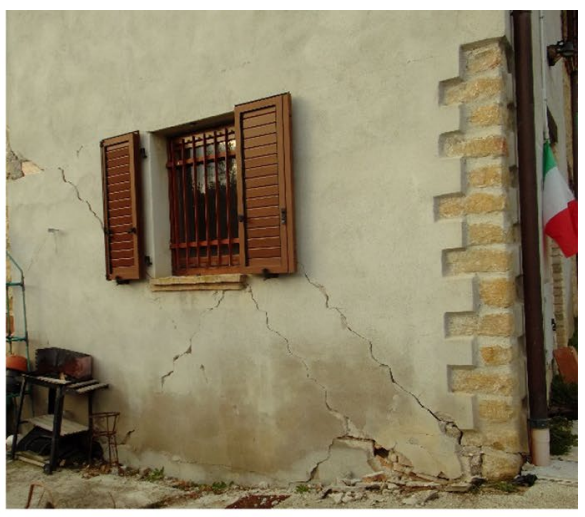

(b)

Fig. 7 Modern Buildings (URM-3): (a) building damaged from 2009 earthquake in L'Aquila (Abruzzi region), (b) building damaged from 2016 to 17 Central Italy earthquake in San Severino Marche (Marche Region) 
mechanisms, constraining the construction to behave in-plane: diagonal-cracks extended from R.C. rings up to the bottom of piers are clearly recognizable.

\subsection{Semi-modern buildings}

Ancient, Improved-Ancient and Modern masonry buildings represent the most prominent typologies on the Italian territory. Despite this, in the zone hit by earthquakes between 1909 and 1937 and however before 1937 in non-seismic zones, it is not uncommon to recognize hybrid typologies, here indicated as Semi-Modern Buildings (URM-4).

$U R M-4$ buildings are erected in a transition age that marks the passage from Ancient or Improved-Ancient to Modern Buildings, i.e. constructed in the period necessary for making mandatory the Codes released in the zones affected by earthquakes. As a result, new anti-seismic constructional rules were not all respected, even because not fully known by the workers.

Floors are made with R.C. or steel beams - provided or not of a top reinforced slabpoorly connected to the vertical walls. Although R.C. or steel ring beams are connected with continuity on the perimeter of the walls, they were often not placed at the floor levels and then not directly connected to the floors themselves. On the other side, R.C. ring beams are however effective to limit local out-of-plane collapse mechanisms. Due to their structural arrangement, seismic behaviour of Semi-Modern Buildings can be considered slightly better than Improved-Ancient buildings but worse than Modern Buildings.

As an example, a Semi-Modern (school) buildings located in Naples, dating back to the 1920 s, is reported in Fig. 8: it can be noted that R.C. ring beam is positioned above the windows opening instead of at floor level.

\subsection{No code-conforming buildings}

The fifth class is represented by the No Code-Conforming Buildings (URM-5). It includes buildings not designed in compliance with the Standards introduced at the age of construction, even if erected before 1937 but after the year of introduction of the corresponding Codes for the zones affected by earthquakes from 1908 to 1937, or after to the introduction of RD (1937) in non-seismic zones.

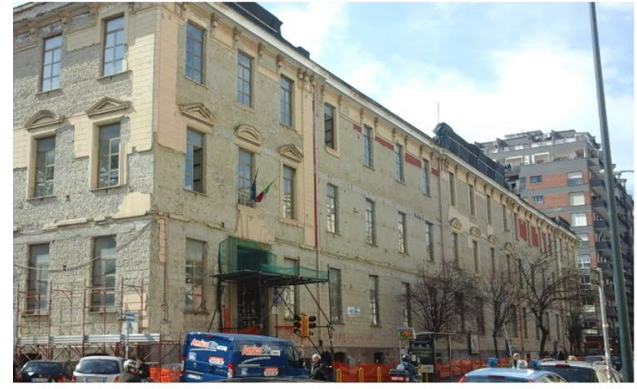

(a)

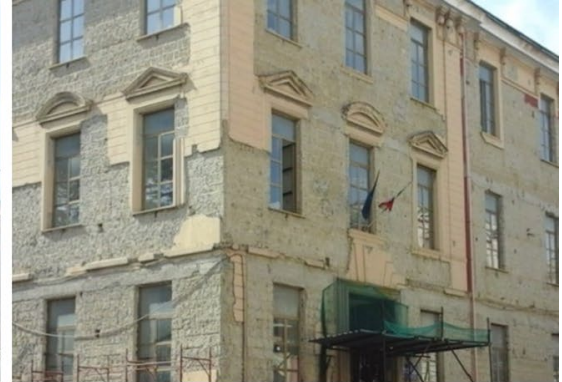

(b)

Fig. 8 Semi-Modern Building (URM-4) located in Naples: (a) external side view, (b) detail of R.C. ring beam 


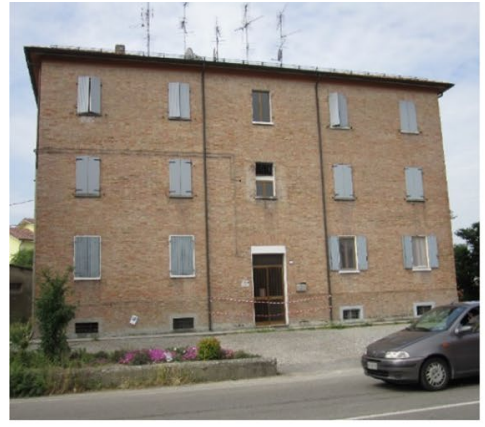

(a)

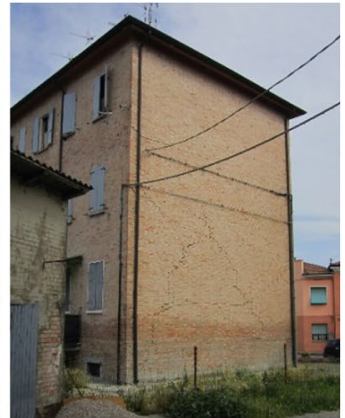

(b)

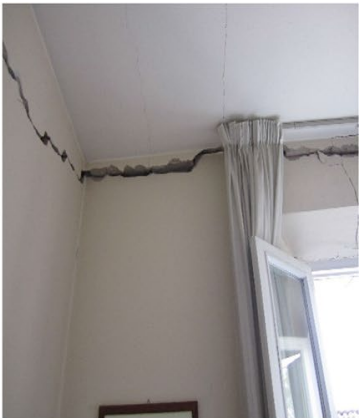

(c)

Fig. 9 No Code-Conforming Building (URM-5) damaged by 2012 Emilia Romagna earthquake and located in Mirandola: a external side view, $\mathbf{b}$ cracks which cross the inter-story level, $\mathbf{c}$ inside horizontal crack due the absence of wall-to-floor connections

Due to their aesthetics (and age of construction), URM-5 buildings appear to be similar to Modern Buildings, but the structural behaviour is completely different from them. The absence of ring beams or equivalent anti-seismic devices makes wall-to-floor and wall-to-wall connections poorly effective. Consequently, their seismic behaviour (dominated by out-of-plane mechanisms) can be assimilated to that of Ancient instead of Modern Buildings.

In Fig. 9, an example of No Code-Conforming Building located in Emilia Romagna Region and damaged by the 2012 earthquake is represented. From one of the external sides, a large crack that crosses the inter-story level (both at first and second story) is visible, while in the internal side a wide horizontal crack at wall-to-floor interface can be noted; such cracks prove the absence of effective wall-to-wall and wall-to-floor connections.

\section{Method for deriving the fragility curves}

In this Section, the methodology to derive typological fragility curves for each building's typology is discussed. Fragility defines the conditional probability of being in or exceeding a particular Damage Measure $(D M)$ given an Intensity Measure $(I M)$ of the earthquake.

Usually, three different groups of parameters to represent the $I M$ are used: (a) Peak Ground parameters, in terms of Acceleration ( $P G A)$ or Velocity $(P G V)$; (b) elastic spectral acceleration or displacement; (c) macroseismic intensity scales.

As a drawback, studies demonstrate that the Peak-Ground parameters are not related to the earthquake's frequency content, duration and number of cycles (Rossetto et al. 2013). On the other hand, spectral values depend on the equivalent vibration period of the structure and a single value cannot be representative for all buildings (also within the same class). Macroseismic scales, instead, can result poorly representative for low and highintensity seismic events (as discussed in Sect. 1).

$D M$ is generally expressed in terms of probability of exceeding an established Limit State, i.e. achievement of maximum displacement capacity (ultimate rotation, maximum inter-story drift, etc.) in one or more structural elements.

In this paper $P G A$ has been employed as the $I M$ of the earthquakes, intended as the maximum ground motion bearable by the structure at $U L S$ measured on soil-type $A$ (i.e., 
on the bed-rock) defined by $I B C$ - 18 . Independently from soil properties and its geographical location on the National territory, soil-type $A$ gives an objective measure of the seismic capacity of the construction as a function of its structural arrangement. Obviously, soil amplification factors defined by the Codes must be applied to obtain a realistic measure of seismic fragility depending on soil characteristics of the investigated area.

Furthermore, analytical correlation between $P G A$ and $M C S$ macroseismic scale has been exploited to represent fragility curves in terms of $M C S$ intensity. Such curves measure the severity of an earthquake as a function of damage level inflicted on the buildings by an earthquakes and people feeling.

$M C S$ scale was firstly calibrated on Italian earthquakes by the seismologist Giuseppe Mercalli and subsequently detailed (enlarged) for assuming European significance (i.e., effects produced by other European earthquakes on buildings were included). Being calibrated on features of Italian earthquakes and damaging suffered by Italian buildings, $M C S$ has been considered as a representative intensity measure within the research purposes.

As $D M$, the attainment of $U L S$ condition by the structure has been chosen. It corresponds to the achievement of the maximum drift of the structural elements when dominated by an in-plane behaviour of the walls, and to the activation of overturning mechanisms in the case of out-of-plane response.

\subsection{Dataset for derivation of fragility curves}

The proposed fragility model is valid for the large-scale vulnerability assessment of typical Italian masonry building stock. For this reason, it refers to low-rise masonry buildings having a number of storeys ranging from 2 to 4 .

Values of $I M$ and the related statistic variables used to define the fragility functions have been obtained through a mechanical approach. Data relative to a sufficient number of numerical analysis results conducted on masonry building prototypes have been collected and analysed to define a database. Such results come in part from previous analyses conducted by the authors on real case study buildings and in part from literature. Some of the papers or books used to elaborate the dataset are: Ghersi et al. (2011), Rota et al. (2014), Calderoni et al. (2016a), b, Cattari et al. (2018), Lagomasino et al. (2019), Morandi et al. (2020) and Sandoli and Calderoni (2021).

Each analysed building has been recognized as belonging to one of the five typological classes defined in Sect. 4. For each of them the maximum, minimum and mean values of the bearable $P G A$ - together with coefficients of variation and standard deviations-have been evaluated. The buildings considered for the dataset have been modelled with equivalent frame or two-dimensional finite element models, while the performed structural analyses are nonlinear static or (in some cases) nonlinear dynamic. Note that results derived by equivalent frame or two-dimensional models only have been considered among those available in literature, because they are affected by lower scattering parentages on the analysis results (Quagliarini et al. 2017).

It should be underlined that the data herein collected are surely less than those available for the empirical methods, but considering that numerical analyses are based on real material properties, real geometry and loads, such data are more realistic in comparison with empirical or mechanical-statistical (i.e., Monte Carlo simulation) evaluations.

Table 2 indicates minimum, maximum and mean values of PGAs (expressed as a percentage of the gravity acceleration $g$ ), standard deviations $(\sigma)$ and coefficients of variation $(\mathrm{CoV})$ for each typology. Note that values of $\sigma$ are different for each class because they are 
Table 2 Data for deriving fragility curves

\begin{tabular}{|c|c|c|c|c|c|c|c|c|}
\hline \multirow[t]{2}{*}{ Structural typology } & \multicolumn{3}{|c|}{ Minimum } & \multicolumn{2}{|l|}{ Maximum } & \multicolumn{3}{|l|}{ Mean } \\
\hline & $\operatorname{CoV}(\%)$ & $P G A / g(-)$ & $\sigma(-)$ & $P G A / g(-)$ & $\sigma(-)$ & $P G A / g(-)$ & $\sigma(-)$ & No. of cases \\
\hline$U R M-1$ & 60 & 0.04 & 0.024 & 0.10 & 0.060 & 0.070 & 0.0420 & 40 \\
\hline$U R M-2$ & 50 & 0.10 & 0.050 & 0.15 & 0.075 & 0.125 & 0.0625 & 35 \\
\hline$U R M-3$ & 40 & 0.12 & 0.048 & 0.20 & 0.080 & 0.160 & 0.0640 & 28 \\
\hline$U R M-4$ & 60 & 0.12 & 0.072 & 0.18 & 0.108 & 0.150 & 0.0840 & 24 \\
\hline$U R M-5$ & 70 & 0.05 & 0.035 & 0.12 & 0.084 & 0.085 & 0.0595 & 20 \\
\hline
\end{tabular}

directly related to $P G A \mathrm{~s}$, while coefficients of variation remain unchanged because they take into account modelling and material uncertainties and different structural arrangements of buildings (even belonging to the same typological class). In the same Table 2, the number of cases (i.e., number of buildings) considered for each building class are also indicated.

Methods to calculate the PGAs are those suggested by IBC-18 and ISR-19 (coherently with the Eurocode 8): (i) linear or nonlinear kinematic analyses for buildings prone to outof-plane behaviour and (ii) nonlinear static or dynamic analyses for buildings dominated by in-plane behaviour.

As it can be noted in Tab. 2, Ancient Buildings (URM-1) represent the most vulnerable typology, while Modern Buildings (URM-3) are those characterized by higher values of $P G A$. This difference is due to the bad seismic behaviour of Ancient Buildings, governed by out-of-plane mechanisms, with respect to the good seismic response of Modern Buildings, characterized by a spatial box-like behaviour. Semi-Modern Buildings (URM-4) show $P G A$ s ranging between $U R M-2$ and $U R M-3$, confirming their hybrid nature. Conversely, structural deficiencies listed in the Sect. 4 for No Code-Conforming Buildings (URM5) affect negatively their seismic behaviour, making their structural response similar to Ancient Buildings.

$P G A$ s relative to $U R M-1$, as well as those of $U R M-4$ and $U R M-5$, are affected by higher coefficients of variation. This mainly depends on the greater uncertainties related to (i) a not well-defined structural behaviour of the walls, (ii) the assumptions made for modelling the out-of-plane structural behaviour of the macro-elements, (iii) the choice of the actual failure mechanisms among those admissible, (iv) constraint conditions of the walls and (v) conventional and constant value of behaviour factors adopted to take into account the (reduced) ductile and dissipative response related to out-of-plane response (assumed equal to 2.0 by ISR-19).

On the contrary, fewer dispersions affect the results relative to the typologies $U R M$ 2 and $U R M-3$ because they are characterized by a clearer in-plane structural behaviour, despite the assumption made for defining the structural models. In these cases, $P G A$ s are calculated on the basis of pushover analyses adopting the N2 method (Fajfar and Gaspersic 2000), in which pushover curve of the multi-degree of freedom structures is transformed into an equivalent bilinear curve relative to a single degree of freedom system and the behaviour factor is calculated as a function of the available ductility of the structure (but however limited to 3.0 by ISR-19 and Eurocode 8).

Also for $U R M-2$ and $U R M-3$ the coefficients of variation remain significant, because modelling uncertainties can significantly affect the in-plane behaviour of the walls (Rota et al. 2014). 
Concerning to correlation of $P G A$ with $M C S$ scale, it is Described in Sect. 6.2.

\subsection{Fragility function}

To process the data listed in Table 2, a Lognormal statistical distribution has been adopted. Literature works demonstrate that this distribution fits correctly empirical or numerical data and that it provides, with sufficient approximation, feasible vulnerability scenarios (Del Gaudio et al. 2019; Donà et al. 2020; Rosti et al. 2020).

Probability Density Function $(P D F)$ of the Lognormal distribution is given by the following formula:

$$
P D F=\frac{1}{I M \mu \sqrt{2 \pi}} \exp \left[-\frac{1}{2}\left(\frac{\ln I M-\mu}{\beta}\right)^{2}\right]
$$

Equation (1) gives back an asymmetric Gaussian bell-curve whit a peak corresponding to the lognormal mean value and which tends to zero at both ends of the curve itself. Coefficients $\beta$ and $\mu$ are the standard deviation and the mean value of the lognormal distribution, respectively. They are related to the standard deviations $(\sigma)$ and values of $P G A$ (minimum, maximum or mean) of the Normal distribution listed in Table 2 through the formulas reported in the following:

$$
\begin{gathered}
\beta=\sqrt{\ln \left(\frac{\sigma^{2}}{P G A}+1\right)} \\
\mu=\ln (P G A)-\frac{\beta^{2}}{2}
\end{gathered}
$$

Table 3 groups the values of $\beta$ and $\mu$ calculated through the Eqs. (2) and (3), respectively.

The Cumulative Density Function $(C D F)$-i.e. the conditional probability of being in or exceeding a particular $D M$ given an $I M$ of the earthquake-provides the fragility curve. It is obtained by integrating Eq. (1) and assume the following expression:

$$
C D F=P[D M>d m \mid I M]=\frac{1}{2}+\frac{1}{2} \operatorname{erf}\left[\frac{\ln I M-\mu}{\beta \sqrt{2}}\right]
$$

\begin{tabular}{|c|c|c|c|c|c|c|}
\hline \multirow[t]{2}{*}{ Structural typology } & \multicolumn{2}{|c|}{ Minimum } & \multicolumn{2}{|c|}{ Maximum } & \multicolumn{2}{|l|}{ Mean } \\
\hline & $\mu$ & $\beta$ & $\mu$ & $\beta$ & $\mu$ & $\beta$ \\
\hline$U R M-1$ & 3.622 & 0.307 & 4.538 & 0.307 & 4.182 & 0.307 \\
\hline$U R M-2$ & 4.561 & 0223 & 4.967 & 0.223 & 4.784 & 0.223 \\
\hline$U R M-3$ & 4.757 & 0.148 & 5.268 & 0.148 & 5.044 & 0.148 \\
\hline$U R M-4$ & 4.721 & 0.307 & 5.126 & 0.307 & 4.944 & 0.307 \\
\hline$U R M-5$ & 3.813 & 0.398 & 4.688 & 0.398 & 4.343 & 0.398 \\
\hline
\end{tabular}

Table 3 Values of mean $(\mu)$ and standard deviation $(\beta)$ of the Lognormal distribution 

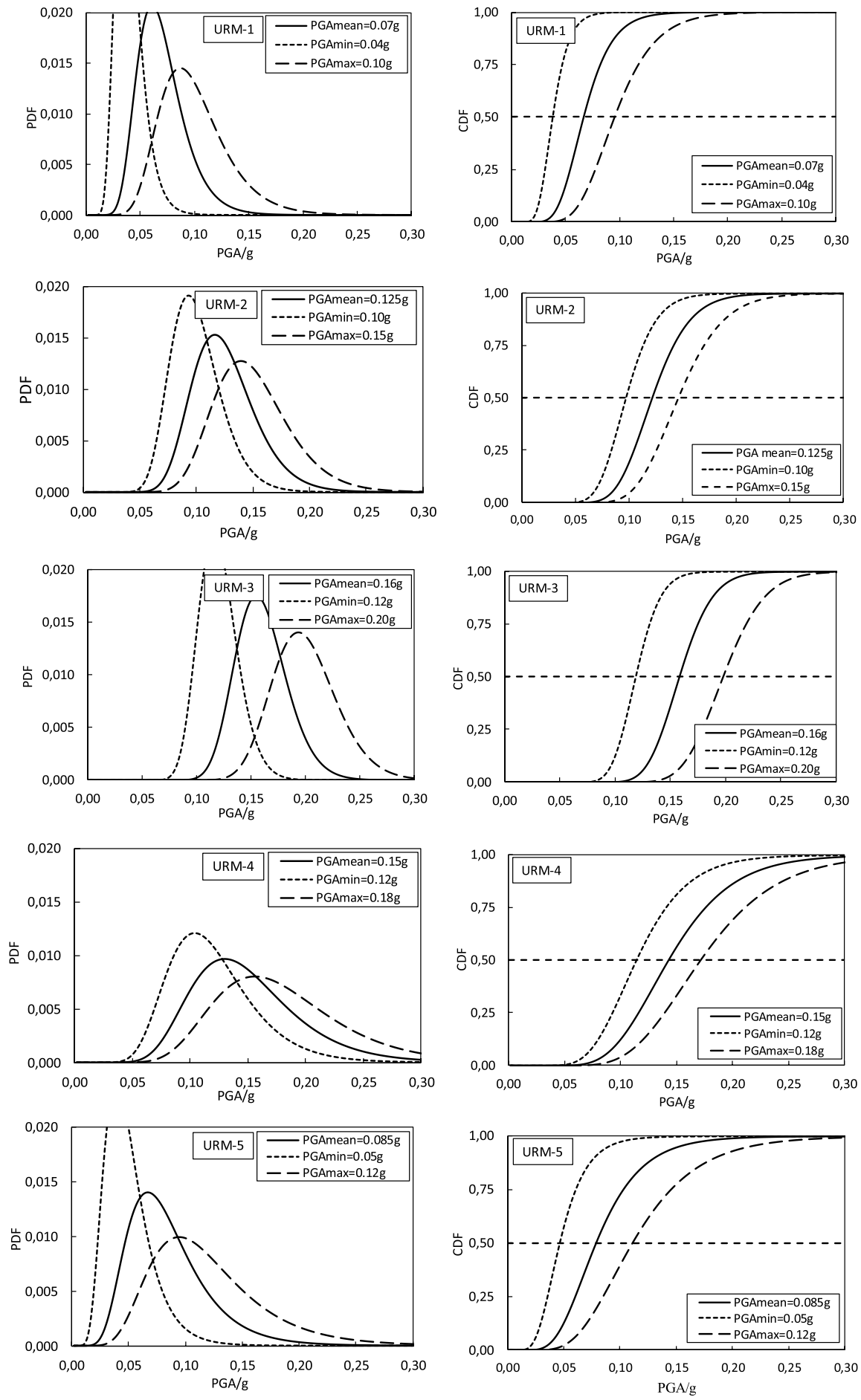

Fig. 10 Probability and Cumulative density functions for the five building classes 


\section{Typological fragility curves at ULS for the five buildings classes}

\subsection{Fragility curves in terms of PGA}

Figure 10 reports $P D F$ s and $C D F$ s obtained by using as $I M$ the logarithmic values of $P G A$ at $U L S$ defined through the Eq. (3). IBC-18 (as well as Eurocode 8) defines $U L S$ as the state in which 'after an earthquake, the structure shows heavy damage to the structural elements but preserves a sufficient safety factor against gravity loads and a low safety factor with respect to horizontal actions'.

Each graph in Fig. 10 contains three curves: the first (continuous line) refers to logarithmic coefficients of variation and standard deviations calculated on mean values of $P G A$ s, while the other two (dashed lines) refer to logarithmic coefficients of variation and standard deviations evaluated on minimum and maximum value of $P G A$ s.

To include a range of variability represents a more complete way of representing fragility curves and estimating likely vulnerability scenarios. Such variability arises from the fact that each typological class groups buildings having structural arrangement coherent with the age of construction but, due to different structural features, details and material properties, their seismic vulnerability can be different also within the same building class.

In Fig. 11a and b, probability and cumulative density functions of the five structuraltypological classes of Italian $U R M$ buildings are compared. The figure highlights that going from the typology $U R M-1$ to $U R M-3$ the curves are spaced and shifted onward: with reference to a $50 \%$ of probability of exceeding $(C D F)$, seismic capacity increased up to 3 times passing from $U R M-1$ to $U R M-3$. Even more interesting is the significant gap between the fragility curve of $U R M-1$ with respect to $U R M-2$, underlining the greater seismic vulnerability of the Ancient Buildings with respect to Improved Ancient Buildings.

Without any specific reference to the $P G A$ values, which are based on a conventional calculation, preliminary and general observations on seismic vulnerability assessment at territorial-scale can be given. Fragility curves evidence that: $a$ ) the high level of seismic vulnerability of an area is conditioned by the percentage of Ancient Buildings contained in it; $b$ ) light and low-invasive strengthening interventions (such as horizontal ties) can reduce significantly the seismic vulnerability at territorial scale because they change the

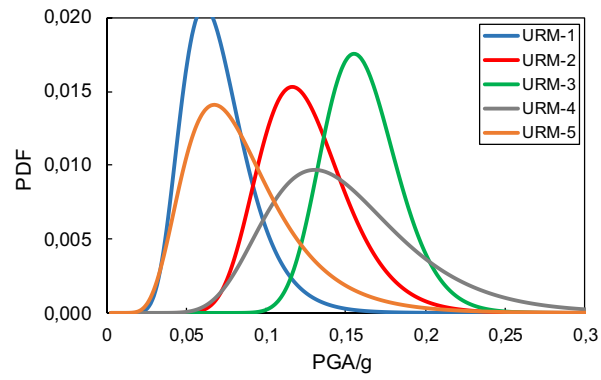

(a)

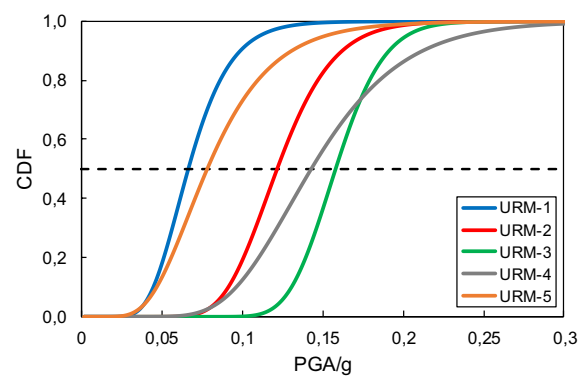

(b)

Fig. 11 Comparison among (a) probability and (b) cumulative density functions for the five building's classes 
structural behaviour from $U R M-1$ to $U R M-2$. It is evident that, to obtain a significant reduction of seismic vulnerability with a lower expense, a correct territorial-scale planning of interventions should prefer the adoption of light interventions.

\subsection{Correlation with Mercalli-Cancani-Sieberg scale}

Macroseismic intensity scales represent an important tool to evaluate seismic damage scenarios at territorial-level. $M C S$ scale, as well as EMS98, takes into account the severity of an earthquake as a function of both damage level produced to the buildings and people feeling.

$M C S$ scale includes 12 intensity degrees (from 'instrumental' to 'apocalyptic' earthquake) and describes the total damage of the buildings based on an observational approach, without specifying their structural features (Tab. 4). This fact-which might seem in contrast with the proposed classification-has been exploited to define a measure of the expected damaging for increasing levels of seismic intensity.

Table 4 Mercalli-Cancani-Sieber scale

\begin{tabular}{|c|c|}
\hline Grade & Effect on buildings and peoples \\
\hline 1-Instrumental & Not felt by many people unless in favourable conditions \\
\hline 2-Weak & $\begin{array}{l}\text { Felt only by a few people at best, especially on the upper floors of buildings. Delicately } \\
\text { suspended objects may swing }\end{array}$ \\
\hline 3-Slight & $\begin{array}{l}\text { Felt noticeably by people indoors, especially on the upper floors of buildings. Many do not } \\
\text { recognize it as an earthquake. Standing motor cars may rock slightly. Vibration similar } \\
\text { to the passing of a truck. Duration estimated }\end{array}$ \\
\hline 4-Moderate & $\begin{array}{l}\text { Felt indoors by many people, outdoors by a few people during the day. At night, some } \\
\text { awakened }\end{array}$ \\
\hline 5-Rather strong & $\begin{array}{l}\text { Felt outside by most, may not be felt by some people in non-favourable conditions. Dishes } \\
\text { and windows may break and large bells will ring. Vibrations like train passing close to } \\
\text { house }\end{array}$ \\
\hline 6-Strong & $\begin{array}{l}\text { Felt by all; many frightened and run outdoors, walk unsteadily. Windows, dishes, glass- } \\
\text { ware broken; books fall of shelves; some heavy furniture moved or overturned; a few } \\
\text { instances of fallen plaster. Damage slight }\end{array}$ \\
\hline 7-Very strong & $\begin{array}{l}\text { Difficult to stand; furniture broken; damage negligible in building of good design and } \\
\text { construction; slight to moderate in well-built ordinary structures; considerable damage } \\
\text { in poorly built or badly designed structures; some chimneys broken. Noticed by people } \\
\text { driven motor cars }\end{array}$ \\
\hline 8-Destructive & $\begin{array}{l}\text { Damage slight in specially designed structures; considerable in ordinary substantial build- } \\
\text { ings with partial collapse. Damage great in poorly built structures. Fall of chimneys, } \\
\text { factory stacks, columns, monuments, walls. Heavy furniture moved }\end{array}$ \\
\hline 9-Violent & $\begin{array}{l}\text { General panic; damage considerable in poorly designed structures, wall designed frame } \\
\text { structures thrown out of plumb. Damage great in substantial buildings, with partial col- } \\
\text { lapse. Buildings shifted off foundations }\end{array}$ \\
\hline 10-Intense & $\begin{array}{l}\text { Some well build wooden structures destroyed; most masonry and frame structures } \\
\text { destroyed with foundation. Rails bent }\end{array}$ \\
\hline 11-Extreme & Few, if any masonry structures remain standing. Bridges destroyed. Rails bent greatly \\
\hline 12-Cataclysmic & $\begin{array}{l}\text { Total destruction-everything is destroyed. Lines of sigh and level distorted. Objects } \\
\text { thrown into air. The ground moves in waves or ripples. Large amounts of rock move } \\
\text { position. Landscape altered, or levelled by several meters. In some cases, even the routes } \\
\text { of rivers are changed }\end{array}$ \\
\hline
\end{tabular}


Table 5 Values of $I_{\mathrm{MCS}}$ for different Limit States

\begin{tabular}{lllc}
\hline & URM-1 & URM-2 & URM-3 \\
\hline$D L S$ & 6 & 7 & 8 \\
$U L S$ & 7 & 8 & 9 \\
$C L S$ & 8 & 9 & 10 \\
\hline
\end{tabular}

Fig. 12 Fragility curves in terms of MCS scale

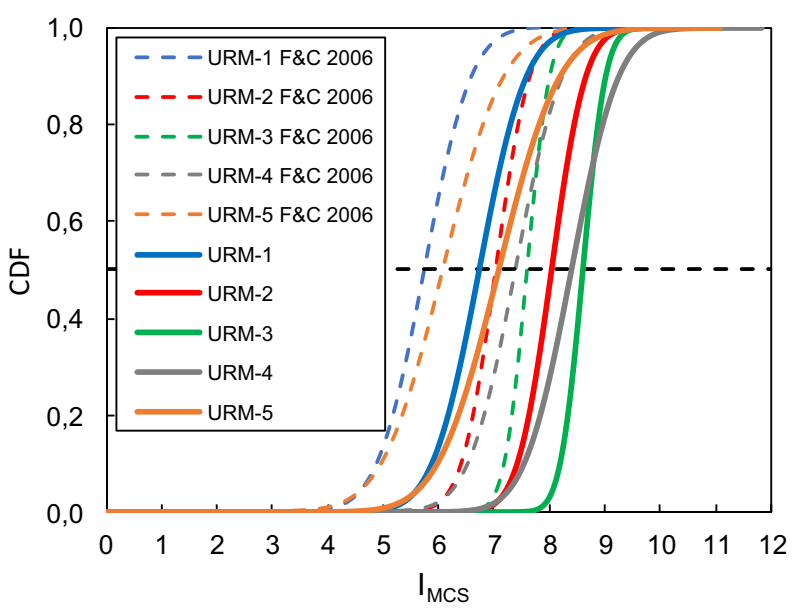

To this aim, a correlation between $M C S$ and the structural typological classification herein proposed has been identified and three damage levels for each building class defined. By reading Tab. 4, the typologies URM-1, URM-2 and URM-3 can be recognized in the MCS scale: URM-1 are those defined as poorly built or badly designed constructions, URM-2 are described as well-built ordinary structures and URM-3 as good designed constructions. Moreover, it can be noted that the damage to buildings starts from Grade 6 (strong) up to Grade 11 (extreme), while effects on people and things are only considered before Grade 6. Three increasing levels of damage, defined as slight, considerable and great are identified in MCS scale and associated to the building class for different damage Grades. Compared with the modern Codes for constructions, such levels of damage can be identified as the Damage Limit State $(D L S)$, Ultimate Limit State $(U L S)$ and Collapse Limit State $(C L S)$, respectively. A schematic representation of the association between typological classes and $M C S$ intensity measure $I_{\mathrm{MCS}}$ (i.e., damage level) is reported in Tab. 5.

To obtain fragility curves in terms of $\mathrm{I}_{\mathrm{MCS}}$, correlation formulas between the $P G A$ and $I_{\mathrm{MCS}}$ have been adopted. Different formulations are given in literature, all expressed in the form:

$$
\log (P G A)=a+b I_{M C S}
$$

where $a$ and $b$ are two coefficients provided in literature. In this study, $a=-1.33$ and $b=0.20$ suggested by Faccioli and Cauzzi (2006) have been adopted. Such coefficients are obtained by means of regression analyses referred to 27 records of Italian earthquakes and to the related damage survey. Therefore, also different values for the coefficient $a$ and $b$ 
used for correlating $P G A$ with $I_{\mathrm{MCS}}$ are available in literature which provide comparable results (Faenza and Michelini, 2010; Cescatti et al. 2020).

In Fig. 12, the fragility curves in terms of $I_{\mathrm{MCS}}$ obtained adopting the coefficients provided by Faccioli and Cauzzi (2006) are represented with dashed lines. With regards to an average value of probability of exceedance $(C D F=50 \%)$, it can be noted that such curves provide a little underestimation of damage level with respect to that expected from MCS scale (continuous line). As an example, for $U R M-1$, at $50 \%, I_{\mathrm{MCS}}=5$ is expected by Faccioli and Cauzzi's formula, while $I_{\mathrm{MCS}}=6$ is suggested by $M C S$ scale. To better tune the correspondence between the $\mathrm{I}_{M C S}$ provided by the Faccioli and Cauzzi's formula and $\mathrm{I}_{M C S}$ given by MCS scale, the authors suggest to shift by one Grade the results provided by Eq. (5), thus obtaining the curves with continuous line reported in Fig. 12.

These fragility curves give a continuous representation of the probability of exceeding the $U L S$ at each damage grade (from grade 1 to grade 12), separately for each building's class.

Note that in the case of methods based on statistical analyses of damage (i.e., empirical methods), the fragility curves referred to different Damage States (DSs) or Limit States are easily representable (generally defined according to DSs given by EMS98). In this paper, it was difficult to elaborate different curves for each Limit State because results found in literature often do not allow to estimate reliable values of $P G A$ corresponding to them.

The curves in Fig. 12 show that high-damage is predictable in almost all buildings typologies for earthquakes with $I_{\mathrm{MCS}}$ about of 8-9: this result reflects the post-seismic damage scenarios observed in the Italian historical centres following to the most destructive earthquakes. In fact, after the Irpinia's, L'Aquila's or Central Italy's earthquakes, all characterized by high values of $I_{\mathrm{MCS}}$ (Fig. 2), buildings resulted heavily damaged: URM-I totally or partially collapsed out-of-plane, while $U R M-2$ and $U R M-3$ heavily damaged inplane (Calderoni et al. 2011, 2020; Penna et al. 2014).

As expected, the damage scenario for the classes URM-1 and URM-5 resulted higher than $U R M-2, U R M-3$ and $U R M-4$, also in terms of $I_{\text {MCS }}$. Referring to mean values of $I_{\mathrm{MCS}}$ (between 6 and 8) the percentage of buildings $U R M-1$ and $U R M-5$ which will suffer damage is greater than $U R M-2, U R M-3$ and $U R M-4$. Moreover, the different damaging becomes more relevant for low values of $I_{\mathrm{MCS}}$ and less relevant for high values of $\mathrm{I}_{\mathrm{MCS}}$ (where the curves tend to the asymptotic value of $100 \%$ of probability of exceedance).

\section{Comparison with EMS98}

Fragility curves obtained through the hybrid method have been compared with those empirical based on EMS98 scale. Some researches adopted such scale to derive empirical fragility curves for Italian URM buildings typologies (Lagomarsino and Giovinazzi 2006; Del Gaudio et al. 2019; Rosti et al. 2020).

$E M S 98$, useable at the European level, classifies the masonry buildings in seven different typologies (mainly differentiated as a function of masonry type) and to each of them associates a vulnerability class varying from $A$ to $F$ (Fig. 13). Moreover, each typology is susceptible of a $D S$, from $D S 1$ to $D S 5$, as illustrated in Table 6.

Fragility curves developed by Lagomarsino and Cattari (2014) - in turns derived from the macroseismic approach presented in Lagomarsino and Giovinazzi (2006) - have been considered for comparison purposes. Based on EMS98, they developed a multi-damage 
Fig. 13 Correspondence between vulnerability classes of EMS98 and proposed classification

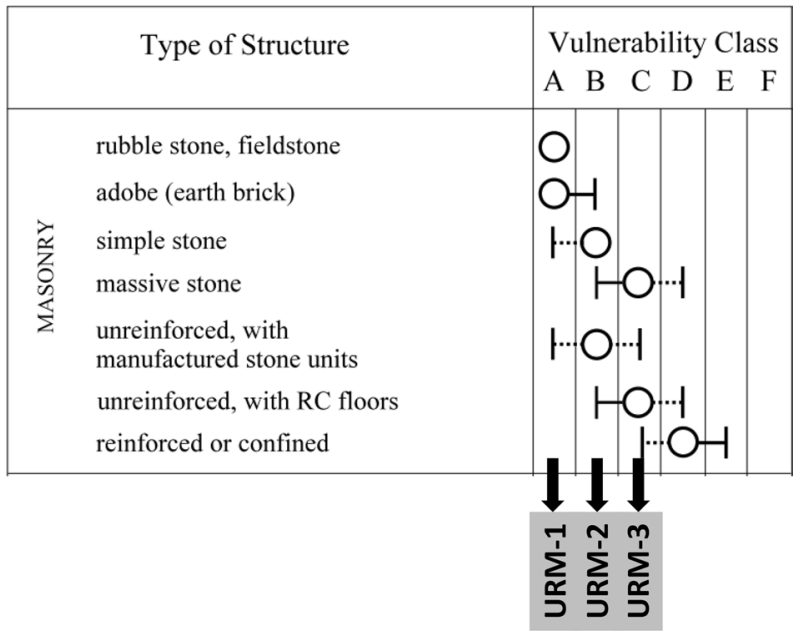

fragility model that for each vulnerability class (from $A$ to $F$ ) define five fragility curves as a function of the Damage States.

To compare the curves, an analogy between the vulnerability classes defined by EMS 98 with respect to those defined in this paper has been established. Such correspondence is reported in Fig. 13: vulnerability class $A$ of the EMS98 (which represents the highest degree of vulnerability) corresponds to $U R M-1$, vulnerability class $B$ to $U R M-2$ and vulnerability class $C$ to $U R M-3$. As regards $U R M-4$ and $U R M-5$, no correspondence can be defined, but at most they could be assimilated to class $C$ and $A$, respectively.

This analogy finds its justification in the description of building classes reported in the EMS98 document. In fact, for 'rubble stone, fieldstone' (vulnerability class A) it clarifies that are 'traditional constructions provided of very low seismic resistance, floors are typical of wood and no provide horizontal stiffening'. This description corresponds to that provided for URM-1.

As regards 'simple stone' masonry (vulnerability class $B$ ) is specified that 'these hewn stone are arranged in the constructions to improve the strength of the structure, e.g. using large stone to tie in the walls at the corner'. Despite that ties are not explicitly mentioned, it is reasonable that these provisions encourage an in-plane behaviour of the walls. Thus, class $B$ has been considered coincident with $U R M-2$.

As regards ' $U R M$ brick with R.C. floors' (vulnerability class $C$ ), EMS98 clarifies that the 'walls are connected and tied together with a rigid floor slab with ring beams, a boxlike system is created which effectively reduces the risk of out-of-plane collapse of the walls, or the separation of drift of intersecting perpendicular walls'. It is evident that such description coincides with that provided for URM-3.

As above-specified, fragility curves proposed in this paper are referred to $U L S$ only: by analogy it coincides with the DS4 defined by EMS98.

Figure 14 compares the curves relative to the classes $A, B$ and $C$ obtained adopting logarithmic mean $(\mu)$ and standard deviations $(\beta)$ relative to the Damage State DS4 (dashed lines) defined in Lagomarsino and Cattari (2014) with the average fragility curves relative to the classes $U R M-1, U R M-2$ and $U R M-3$ (continuous line), respectively.

Comparisons show that (a) the slope of the fragility curves defined in this paper are greater than those of the macroseismic approach; (b) the values of $P G A$ at $50 \%$ of 


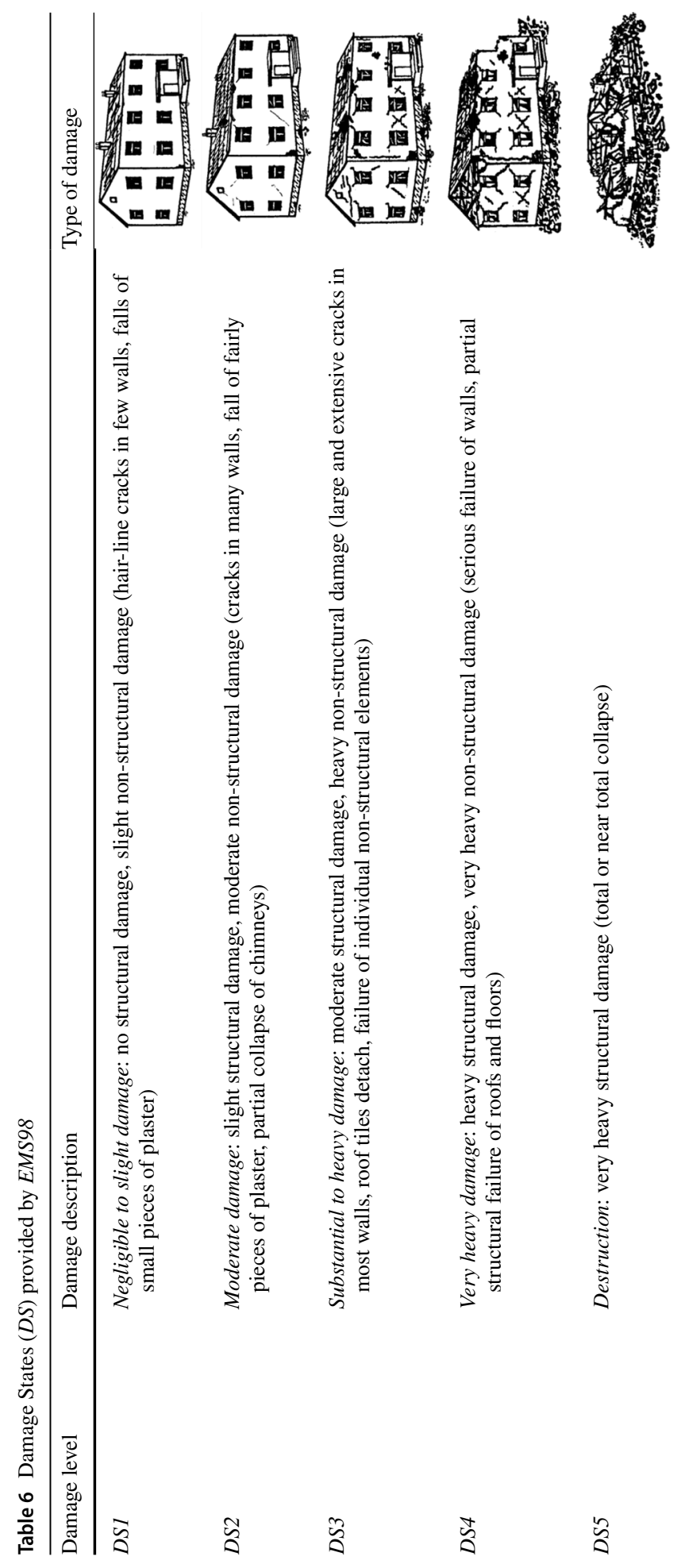


Fig. 14 Comparison between EMS98 (DS4) and the proposed fragility curves

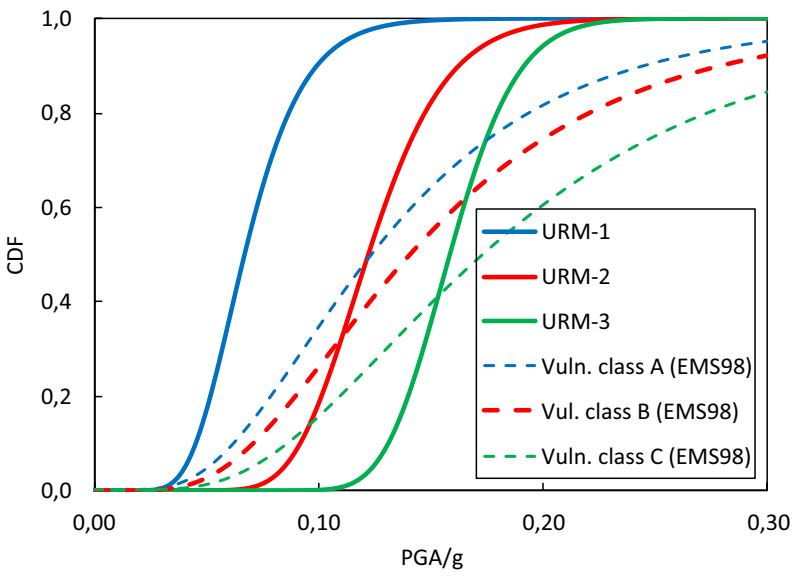

Tab. 7 Comparison among logarithmic mean and standard deviation with literature values relative to damage State DS4

\begin{tabular}{|c|c|c|c|c|c|c|c|}
\hline \multirow[t]{2}{*}{ Structural typology } & \multirow[t]{2}{*}{$\begin{array}{l}\text { Equivalence } \\
\text { with EMS98 }\end{array}$} & \multicolumn{2}{|c|}{ Present paper } & \multicolumn{2}{|c|}{$\begin{array}{l}\text { Lagomarsino and } \\
\text { Cattari (2014) }\end{array}$} & \multicolumn{2}{|c|}{$\begin{array}{l}\text { Donà et al. } \\
\text { (2020) }\end{array}$} \\
\hline & & $\mu$ & $\beta$ & $\mu$ & $\beta$ & $\mu$ & $\beta$ \\
\hline$U R M-1$ & Class A & 4.183 & 0.307 & 1.943 & 0.533 & 3.430 & 0.773 \\
\hline$U R M-2$ & Class B & 4.784 & 0.223 & 3.209 & 0.538 & n.a.* & n.a.* \\
\hline$U R M-3$ & Class C & 5.044 & 0.148 & 5.305 & 0.541 & 6.520 & 0.795 \\
\hline
\end{tabular}

*n.a.-not available

probability are best quantified, especially between $U R M-2$ and the vulnerability class B and between $U R M-3$ and vulnerability class $C$. In its place, a greater dispersion of $U R M-1$ with respect to the vulnerability class $A$ resulted. A comparison among the values of $\mu$ and $\beta$ with respect to those found in Lagomarsino and Cattari (2014) and in Donà et al. (2020) is reported in Table 7 .

Concerning the point (a), the different slopes between the curves relative to the vulnerability classes $A, B$ and $C$ and those proposed in the present paper are due to the values of $\beta$. In fact, despite that the numerical values of $\beta$ vary slightly compared to that provided in Lagomasino and Cattari (2014) (as well as for Donà et al. 2020), they induce significant variation of slopes. This probably depends on the fact that the EMS98 classifies the buildings as a function of materials and type of horizontal and vertical structures only, while the proposed classification takes also into account the seismic performance of the constructions. Then, in the latter case, it is reasonable that the structural response of the buildings is more homogeneous and characterized by lower values of $\beta$.

With respect to empirical-based approaches, different values of $\mu$ and $\beta$ in the hybrid method are imputable to the cautionary nature of the methods used to assess the seismic capacity of masonry buildings. In fact, to cover uncertainties, a series of coefficients (such as safety factors of materials, confidence factor, knowledge level, behaviour factor, etc.), less or more correspondent to the real situations, are suggested by the Codes for evaluating the seismic capacity (i.e., the $P G A$ ). Obviously, in the case of empirical methods such 
coefficients are not considered, because based on a direct measure of the real observed damaging. By contrast, it should be also considered that the empirical approaches rely on the subjective judgement (and opinion) of the detector, which often affect the results also significantly.

\section{Conclusions}

A hybrid seismic fragility model for large-scale seismic vulnerability assessment of residential Italian masonry building stock has been proposed in this paper. The method combines the observational expert-judgment and mechanical approaches to derive typological fragility curves.

Based on observational expert-judgment, five typological classes of masonry buildings representative of the Italian URM constructions have been defined. Classification focuses on a strict correlation between age of construction, structural typology and observed seismic behaviour and damaging after earthquakes. These three parameters contribute together to define the structural behaviour of the typology, considered as the real discriminant of the subdivision in structural-typological classes.

Contrary to other literature classifications, the proposed one is not based on the statistical processing of damage data derived from post-earthquake surveys. It is the result of the authors' experience developed in-field after the most severe earthquakes occurred in Italy in the last forty years and in academia.

The mechanical approach, instead, allowed to derive typological fragility curves separately for each typological class elaborated on the ULS damage state. At this aim, results of numerical analyses have been collected and elaborated to derive seismic Intensity Measures (in this study chosen as the Peak-Ground Acceleration (PGA) bearable by each building class at Ultimate Limit State).

Three different curves have been developed - each of them obtained considering as $I M$ the mean, maximum and minimum value of $P G A$ s-allowing for a more complete representation of the fragility. Such variability takes into account the different structural features and constructional details that changes as a function of the geographic area (also for the same typological class).

To represent the severity of an earthquake as a function of damage level inflicted to the buildings for increasing earthquake intensity, fragility curves in terms of Mercalli-CancaniSieberg macroseismic scale have been also elaborated.

The obtained fragility curves, in terms of both PGA and $I_{\mathrm{MCS}}$, reflect the real vulnerability and post-seismic damage scenarios observed in the small Italian urban areas hit by severe earthquakes. Ancient Buildings (URM-1) have the highest vulnerability and are exposed to a high damaging also for low/medium-intensity earthquakes. Conversely, Improved-Ancient Buildings (URM-2) strengthened also with light local interventions or Modern Masonry Buildings (URM-3) can resist to medium/high-intensity earthquakes effectively.

The hybrid method-based fragility curves have been also compared with those empirical derived according to the EMS98 scale. Comparisons show that mean values of $P G A$ at $50 \%$ of probability of exceedance are comparable, while the slope of the hybrid curve is greater than those empirical. Such comparison highlighted that differences between the hybrid and macroseismic approaches are justified (and almost unavoidable) by the approximation inherent in the method adopted to derive the values of $P G A$ within the mechanical method. 


\section{Appendix: Table for description of the structural-typological classes}

\section{Ancient Bldgs (URM-1)}

Definition

Age of construction

Description of the components
Buildings with full-height vertical masonry walls and curved or flat floors not effectively connected to the masonry walls. No diffused ties or similar seismic devices are present

Buildings erected before 1937 in non-seismic zones

Buildings erected before of the year of introduction of the specific seismic Codes for zones hit by earthquakes from 1908 to 1937

Masonry walls: made with materials available into the geographic area

Floors: deformable in-plane

Strengthening interventions:
In the Apennine areas or in those characterized by the presence of hard stones: irregular or semiirregular masonry stones with lime mortar

In the Apennine areas or in those characterized by the presence of soft stones (tuff, sandstones, limestone): regular soft stone masonry with lime (or sometimes pozzolanic) mortar

In the lowland areas characterized by the presence of clay (NorthCentral Italy): regular clay-brick masonry with lime mortar

Masonry vaults with simple or double curvature

Solid-wood beams not effectively connected to the vertical walls and without in-plane stiffening devices

Iron beams not effectively connected to the vertical walls and without in-plane stiffening devices

None

Improved-ancient Bldgs (URM-2)

Definition

Age of construction
Buildings with full-height vertical masonry walls and curved or flat floors not effectively connected to the masonry walls, but provided with effective wall-to-wall connection systems (i.e., ties or similar) at each story

Buildings erected before 1937 in non-seismic zones, but which have been repaired as a consequence of seismic events

Buildings erected before the year of introduction of the specific seismic Codes for zones hit by earthquakes from 1908 to 1937 (seismic zones), but which have been repaired as a consequence of seismic events 
Improved-ancient Bldgs (URM-2)

Description of the components Masonry walls: made with materials available into the geographic area

In the Apennine areas or in those characterized by the presence of hard stones: irregular or semiirregular masonry stones with lime mortar

In the Apennine areas or in those characterized by the presence of soft stones (tuff, sandstones, limestone): regular soft stone masonry with lime (or sometimes pozzolanic) mortar

In the lowland areas characterized by the presence of clay (North-central Italy): regular clay-brick masonry with lime mortar

Floors: deformable in-plane

Masonry vaults with simple or double curvature

Solid-wood beams not effectively connected to the vertical walls and without in-plane stiffening devices

Iron beams not effectively connected to the vertical walls and without in-plane stiffening devices

Strengthening interventions:

Steel ties with circular or squared cross-section connected at the ends of the walls by end-plates

Solid wooden beams or iron beams effectively connected to the vertical masonry walls

Hot-rolled steel profiles connected with continuity to the masonry walls

Modern Bldgs (URM-3)

Definition

Buildings with vertical masonry walls interrupted at the inter-story level by floors equipped with R.C. ring beams 
Modern Bldgs (URM-3)

Age of construction

Buildings erected after 1937 in the non-seismic zones

Buildings erected before 1937, but after the year of introduction of specific seismic rules for those zones declared as seismic from 1908 to 1937

Description of the components Masonry walls: made with materials available into the geographic area

In the Apennine areas or in those characterized by the presence of hard stones: irregular or semiirregular listed masonry stone, with weak (cement and lime) or cementitious mortar

In the areas characterized by the presence of soft stones (tuff, sandstones, limestone): irregular soft stone masonry with weak (cement and lime) or cementitious mortar In the lowland areas characterized by the presence of clay (North-central Italy): regular brick masonry with weak (cement and lime) or cementitious mortar

Everywhere (generally in more recent constructions): regular concrete hollow-brick masonry with weak (cement and lime) or cementitious mortar

Floors: stiff or semi-deformable R.C. floors made with light-weight in-plane blocks (cast in-situ or semi prefabricated), provided or not with reinforced slab

Floors with iron beams inserted in perimetral R.C. ring beams effectively connected to them. Can or not to be provided with reinforced slab

Semi-modern Bldgs (URM-4)

Definition

Buildings with vertical masonry walls and R.C. or steel floors. R.C. ring beams are not effectively connected to the floors and often not placed at the floor level (but below them) 
Semi-modern Bldgs (URM-4)

Age of construction

Buildings erected before 1937 but after the year of introduction of specific Codes for the zones affected by earthquakes from 1908 up to 1937 (and then declared as seismic zones before of 1937)

Buildings erected before 1937 in the non-seismic areas, but constructed according to the rules relative to buildings erected in the zones declared as seismic from 1908 to 1937

Description of the components Masonry walls: made with materi- In the Apennine areas or in those als available into the geographic characterized by the presence of area hard stones: irregular or semiirregular listed masonry stone, with weak (cement and lime) or cementitious mortar

In the areas characterized by the presence of soft stones (tuff, sandstones, limestone): irregular soft stone masonry, with weak (cement and lime) or cementitious mortar

In the lowland areas characterized by the presence of clay (North-central Italy): regular clay-brick masonry, with weak (cement and lime) or cementitious mortar

Everywhere (generally in the more recent constructions): regular concrete hollow-brick masonry with weak (cement and lime) or cementitious mortar

Floor: stiff or semi-deformable in-plane
R.C. floors made light-weight blocks (cast in-situ or semi prefabricated), provided or not with reinforced slab. They are not connected with not with continuity to the masonry walls

Floors with iron beams inserted in perimetral R.C. ring beams end well-connected to them (when both are placed at the same height). They can be provided or not with R.C. slab

No code-conforming Bldgs (URM-5)

Definition

Buildings with full-height vertical masonry walls, with floors not effectively connected to the masonry walls and not provided with R.C. ring beams 
No code-conforming Bldgs (URM-5)

Age of construction

Buildings erected after 1937 in non-seismic zones

Buildings erected before 1937 but after the year of introduction of the corresponding Codes for the zones affected by earthquakes from 1908 to 1937

Description of the components Masonry walls: made with materials available into the geographic area

Floor systems: stiff or deformable in-plane

In the Apennine areas or in those characterized by the presence of hard stones: irregular or semiirregular listed masonry stone, with weak (cement and lime) or cementitious mortar

In the areas characterized by the presence of soft stones (tuff, sandstones, limestone): irregular soft stone masonry, with weak (cement and lime) or cementitious mortar

In the lowland areas characterized by the presence of clay (North-central Italy): regular clay-brick masonry, with weak (cement and lime) or cementitious mortar

Everywhere (generally in the more recent constructions): regular concrete hollow brick masonry (less or more perforated), with weak (cement and lime) or cementitious mortar

R.C. floors made of light-weight blocks (cast in-situ or semi prefabricated), not provided with ring beams and reinforced slab. Floors are simply supported to the masonry walls

Floors with iron beams and hollowblocks, not provided of R.C. slab and simply supported to the perimetral walls

Acknowledgements This work was developed under the financial support of the Italian Department of Civil Protection, within the ReLUIS-DPC 2019-2021 Research Project, which is gratefully acknowledged.

Funding Open access funding provided by Università degli Studi di Napoli Federico II within the CRUICARE Agreement.

Open Access This article is licensed under a Creative Commons Attribution 4.0 International License, which permits use, sharing, adaptation, distribution and reproduction in any medium or format, as long as you give appropriate credit to the original author(s) and the source, provide a link to the Creative Commons licence, and indicate if changes were made. The images or other third party material in this article are included in the article's Creative Commons licence, unless indicated otherwise in a credit line to the material. If material is not included in the article's Creative Commons licence and your intended use is not permitted by statutory regulation or exceeds the permitted use, you will need to obtain permission directly from the copyright holder. To view a copy of this licence, visit http://creativecommons.org/licenses/by/4.0/. 


\section{References}

ATC (1985) Earthquake damage evaluation data for Californian (ATC-13). Applied Technology Council, Redwood City

Baila A, Binda A, Borri A et al. (2011) Manuale delle murature storiche, DEI s.r.l. Tipografia del Genio Civile, Rome, Italy (in Italian)

Belliazzi S, Lignola GP, Di Ludovico M, Prota A (2021) Preliminary tsunami analytical fragility functions proposal for Italian coastal residential masonry buildings. Structures 31:68-79. https://doi.org/10. 1016/j.istruc.2021.01.059

Bernardini A (2004) Classi macrosismiche di vulnerabilità degli edifici in area veneto-friulana. In: Proceedings of the XI ANIDIS conference "L'Ingegneria Sismica in Italia", Genova, Italy (in Italian)

Calderoni B, Cordasco EA, Lenza P, Pacella G (2011) Considerazioni sui danni agli edifici in muratura del centro storico de L'Aquila. L'Università e la ricerca per l'Abruzzo. Il patrimonio culturale dopo il terremoto del 6 Aprile 2009, Textus eds. (Italy) (in Italian)

Calderoni B, Cordasco EA, Sandoli A, Prota A (2016a) Seismic vulnerability assessment of 'ancient' masonry buildings and strengthening intervention strategies, In: Proceedings of the 16th International Brick and Block Masonry Conference, IBMAC 2016, pp 727-736

Calderoni B, Cordasco EA, Pacella G, Onotri E (2016b) Critical issues in the assessment of seismic vulnerability of historical masonry buildings: a study case, In: Proceedings of the 16th International Brick and Block Masonry Conference, IBMAC 2016, pp 611-622

Calderoni B, Cordasco EA, Del Zoppo M, Prota A (2020) Damage assessment of modern masonry buildings after L'Aquila earthquake. Bull Earth Eng 18(5):2275-2301

Calvi GM, Pinho R, Magenes G, Bommer JJ, Restrepo-Velez LF, Crowley H (2006) Development of seismic vulnerability assessment methodologies over the past 30 years. J Earth Tech 43(472):75-104

Carbone IV, Fiore A, Pistone G (2001) Le costruzioni in muratura-interpretazione del comportamento statico e tecniche di intervento. Hoepli, Millan (in Italian)

Cattari S, Camilletti D, Lagomarsino S, Bracchi S, Rota M, Penna A (2018) Masonry Italian codeconforming buildings. Part 3: nonlinear modelling and time-history analysis. J Earthq Eng 22:2010-2040

Ceroni F, Caterino N, Vuoto A (2020) Simplified seismic vulnerability assessment methods: a comparative analysis with reference to regional school building stock in Italy. Appl Sci 10(19):6771

Cescatti E, Salzano P, Casapulla C, Ceroni F, da Porto F, Prota A (2020) Damages to masonry churches after 2016-2017 Central Italy seismic sequence and definition of fragility curves. Bull Earth Eng 18(297):297-329

DPC (2018) Italian Civil Protection, Department of Presidency of Council of Ministers. National risk assessment-overview of potential major disasters in Italy: seismic, volcanic, tsunami, hydrogeological/hydraulic and extreme weather, droughts and forest fire risk, pp 1-135

De Martino G, Di Ludovico M, Prota A, Moroni C, Manfredi G, Dolce G (2017) Empirical damage and actual repair costs on masonry buildings after L'Aquila earthquake. In: Proceedings of the 6th international conference on computational methods in structural dynamics and earthquake engineering. Rodes, Greek

Del Gaudio C, De Martino G, Di Ludovico M, Manfredi G, Prota A, Ricci P, Verderame GM (2019) Empirical fragility curves for masonry buildings after the 2009 L'Aquila, Italy, earthquake. Bull Earth Eng 17:6301-6330

Di Ludovico M et al (2017) The contribution of ReLUIS to the usability assessment of school buildings following the 2016 central Italy earthquake. Bollettino Di Geofisica Teorica Ed Applicata 58(4):353-376

Di Pasquale G, Orsini G, Romeo RW (2005) New developments in seismic risk assessment in Italy. Bull Earth Eng 3(1):101-128

Donà M, Carpanese P, Follador V, Sbrogiò L, da Porto F (2020) Mechanics-based fragility curves for Italian residential URM buildings. Bull Earth Eng. https://doi.org/10.1007/s10518-020-00928-7

EMS98 (1998) Cahiers du centre européen de géodynamique et de séismologie, vol. 15: European Macroseismic Scale 1998. Luxembourg: European Center for Geodynamics and Seiseismology, Luxembur

Eurocode 8 EN 1998-3 (2005): Design of structures for earthquake resistance-Part 3: assessment and retrofitting of buildings. CEN (European Committee for Standardization). Brussels. Belgium

Faccioli E, Cauzzi C (2006) Macroseismic intensities for seismic scenarios, estimated from instrumentally based correlations. In: Proceedings of the 1st European Conference on Earthquake Engineering and Seism, Geneva, Switzerland 
Fajfar P, Gaspersic P (2000) The N2 method for the seismic damage for RC buildings. Earth Eng Struct Dyn 25(1):23-67

Feanza L, Michelini A (2010) Regression analysis of MCS intensity and ground motion parameters in Italy and its application in shakeMap. Geophys J Int 180(3):1138-1152

Gesualdo A, Calderoni B, Sandoli A, Monaco M (2019) Minimum energy approach for the in-plane shear resistance of masonry panels. Ing Sism 36(1):42-53

Ghersi A, Lenza P, Calderoni B (2011) Masonry buildings in the light of new seismic Code. In: Dario Flaccovio (ed), Palermo, Italy (in Italian)

IBC-08, Italian Building Code (2008) Technical code for constructions. Ministry of Transportation and Infrastructures

IBC-18, Italian Building Code (2018). Technical code for constructions. Ministry of Transportation and Infrastructures

ISPRA 2021 (Italian Institute for Protection and environmental research). The Italian geological map (scale 1:100.000). https://www.isprambiente.gov.it/Media/carg/emilia.html

Kappos AJ, Panagopoulos G, Panagiotopoulos C, Penelis G (2006) A hybrid method for the vulnerability assessment of R/C and URM buildings. Bull Earth Eng 4:391-413

L (1962) Law n. 1684 Provisions for buildings, with particular prescriptions for seismic zones. Italian Government November 25, 1962 (in Italian)

Lagomarsino S, Cattari S (2014) Fragility functions of masonry buildings. In: Pitilakis K, Crowley H, Kaynia AM (eds) Chapter 5 in SYNER-G: typology definition and fragility functions for physical elements at seismic risk. Springer, Berlin, pp 111-156

Lagomarsino S, Giovinazzi S (2006) Macroseismic and mechanical models for the vulnerability and damage assessment of current building. Bull Earth Eng 4(4):415-443

Lagomarsino S, Marino S, Cattari S (2019) Seismic assessment of existing URM buildings in codes: comparison between different linear and nonlinear static procedures. In: Proceedings of the 7th international conference on computational methods in structural dynamics and earthquake engineering. Crete, Greek

Magenes G, Penna A, Senaldi IE, Rota M, Galasco A (2014) Shaking table test of a strengthened fullscale stone masonry building with flexible diaphragms. Int J Arch Herit 8:349-375

Mastrodicasa S (1943) Dissesti statici delle strutture edilizie. Hoepli, Milan (in Italian)

MD (1975), Ministerial Decree n. 93. Technical rules for constructions in seismic zones. Italian Government, 8 Apr 1975 (in Italian)

MD (1981) Ministerial Decree n. 219. Provisions for reconstructions and development of urban centers hit by earthquakes, 14 May 1981 (in Italian)

MD (1987) Ministerial Decree n. 285. Technical rules for constructions for design, execution and testing of masonry buildings and their refurbishment. Italian Government, 5 Dec 1983 (in Italian)

MD (1996), Ministerial Decree n. 29. Technical rules of construction in seismic zones. Italian Government, 5 Feb 1996 (in Italian)

ISR-19, Italian Seismic Recommendations n.7/2019 (2019) Instruction for the use of Technical Code for constructions, published by D.M. 17/01/2008. Ministry of Transportation and Infrastructures

Morandi P, Manzini CF, Magenes G (2020) Application of seismic design procedures on three modern URM buildings struck by the 2012 Emilia earthquakes: inconsistencies and improvement proposals in the European codes. Bull Earthq Eng 18:547-580

Pagano M (1968) Edifici in muratura. In: Liguori (ed), Naples, Italy (in Italian)

Pagano M (1990) Costruire in muratura, nuove normative. In: Liguori (ed), Naples, Italy (in Italian)

Penna A, Morandi P, Rota M, Manzini CF, da Porto F, Magenes G (2014) Performance of masonry buildings during the Emilia 2012 earthquake. Bull Earth Eng 12:2255-2273

Polese M, Di Ludivuco M, Gaetani d'Aragona M, Prota A, Manfredi G (2020) Regional vulnerability and risk assessment accounting for local building typologies. Int J Disaster Risk Reduct 43:101400

Quagliarini E, Maracchini G, Clementi F (2017) Uses and limits of the equivalent frame model on existing unreinforced masonry buildings for assessing their seismic risk: a review. J Build Eng 10:166-182

RD 1909, Royal Decree n.193. Technical and hygienic rules for repairs, reconstructions and new constructions of private and public buildings in the zones affected by 28th December 1908 earthquakes, and in precedent ones. Italian Government, 22 Apr 1909 (in Italian)

RD 1915, Royal Decree n.573. Technical anti-seismic rules for countries hit by earthquakes. Italian Government, 11 May 1915 (in Italian)

RD (1920) Royal Decree n. 1285. Technical anti-seismic rules for countries hit by earthquakes. Italian Government August 14, 1920 (in Italian) 
RD (1921) Royal Decree n. 36. Technical anti-seismic rules for countries hit by earthquakes. Italian Government February 12, 1921 (in Italian)

RD 1927, Royal Decree n. 431. Technical and hygienic rules for building for the zones affected by earthquakes. Italian Government, 8 Apr 1927 (in Italian)

RD 1935, Royal Decree n. 640. Technical rules for buildings with particular prescriptions for zoned affected by earthquakes. Italian Government, 22 May 1935 (in Italian)

RD 1937, Royal Decree n.2015. Technical rules for constructions, with particular prescriptions for zones hit by earthquake. Italian Government, 27 Dec 1937 (in Italian)

Rossetto T, Ioannou I, Grant DN (2013) Existing empirical fragility and vulnerability functions: compendium and guide for selection, GEM technical Report 2013-X. GEM Foundation, Pavia

Rosti A, Rota M, Penna A (2020) Empirical fragility curves for Italian URM buildings. Bull Earth Eng. https://doi.org/10.1007/s10518-020-00845-9

Rota M, Penna A, Strobbia CL (2008) Processing Italian damage data to derive typological fragility curves. Bull of Earth Eng 28:933-947

Rota M, Penna A, Magenes G (2010) A methodology for deriving analytical fragility curves for masonry buildings based on stochastic nonlinear analyses. Eng Struct 32:1312-1323

Rota M, Penna A, Magenes G (2014) A framework for the seismic assessment of existing masonry buildings accounting for different sources of uncertainty. Earth Eng Struct Dyn 43(7):1045-1066

Sandoli A, Calderoni B (2021) Methodology for an effective retrofitting strategy of existing masonry buildings: a case study near L'Aquila. Int J Mason Res and Innov 6(2):141-165. https://doi.org/10. 1504/IJMRI.2020.10032219

Sandoli A, Musella C, Lignola GP, Calderoni B, Prota A (2020) Spandrel panels in masonry buildings: effectiveness of the diagonal strut model within the equivalent frame mode. Structures 27:879-893. https://doi.org/10.1016/j.istruc.2020.07.001

Tomazevic M (1999) Series on innovation in structures and construction. Earthquake-resistant design of masonry buildings. Imperial College Press, London

Valluzzi MR (2009) User Manual of Vulnus_4.0, original program by Bernardini GA, Modena RC, Vb version edited by Valluzzi MR, with contributions by Benincà G, Barbetta E, Munari M (in Italian)

Zuccaro G, Cacace F (2015) Seismic vulnerability assessment based on typological characteristics. The first level procedure "SAVE." Soil Dyn Earth Eng 69:262-269

Publisher's Note Springer Nature remains neutral with regard to jurisdictional claims in published maps and institutional affiliations. 